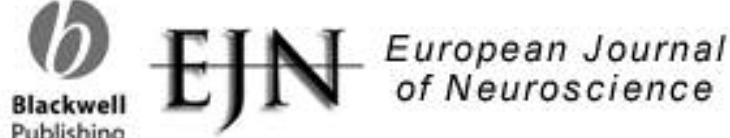

\section{Changes in neuronal response to ischemia in retinas with genetic alterations of somatostatin receptor expression}

\begin{tabular}{|c|c|}
\hline Journal: & European Journal of Neuroscience \\
\hline Manuscript ID: & EJN-2006-10-11423.R2 \\
\hline Manuscript Type: & Research Report \\
\hline $\begin{array}{r}\text { Date Submitted by the } \\
\text { Author: }\end{array}$ & $\mathrm{n} / \mathrm{a}$ \\
\hline Complete List of Authors: & $\begin{array}{l}\text { Catalani, Elisabetta; Universita' della Tuscia, Dip Scienze Ambientali } \\
\text { Cervia, Davide; Universita' della Tuscia, Dip Scienze Ambientali } \\
\text { Martini, Davide; Universita' di Pisa, Dip Biologia } \\
\text { Bagnoli, Paola; Universita' di Pisa, Dip Biologia } \\
\text { Simonetti, Elisa; Universita' di Pisa, Dip Biologia } \\
\text { Timperio, Anna Maria; Universita' della Tuscia, Dip Scienze } \\
\text { Ambientali } \\
\text { Casini, Giovanni; Universita' della Tuscia, Dip Scienze Ambientali }\end{array}$ \\
\hline Key Words: & $\begin{array}{l}\text { neuroprotection, Apoptosis, Glutamate release, Caspases, Bipolar } \\
\text { cells }\end{array}$ \\
\hline
\end{tabular}

\section{S ScholarONE" \\ Manuscript Central}


Changes in neuronal response to ischemia in retinas with genetic alterations of somatostatin receptor expression

Elisabetta Catalani, ${ }^{1}$ Davide Cervia, ${ }^{1}$ Davide Martini, ${ }^{2}$ Paola Bagnoli, ${ }^{2}$ Elisa Simonetti, ${ }^{2}$ Anna Maria Timperio ${ }^{1}$ and Giovanni Casini ${ }^{1}$

${ }^{1}$ Dipartimento di Scienze Ambientali, Università della Tuscia, Viterbo, Italy

${ }^{2}$ Dipartimento di Biologia, Università di Pisa, Pisa, Italy

Running title: sst deletions modulate ischemic retinal damage

Number of pages: 39

Number of figures: 8

Number of tables: 2

Number of words in the manuscript: 9268

Number of words in the Abstract: 249

Number of words in the Introduction: 375 (excluding references)

Corresponding author:

Giovanni Casini, Ph.D.

Dipartimento di Scienze Ambientali

Università della Tuscia

Largo dell'Università snc, Blocco D

01100 Viterbo

Italy

Tel: +390761357040

Fax: +390761357 179

gcasini@unitus.it

Keywords: Apoptosis, Glutamate release, Caspases, Neuroprotection, Bipolar cells 
sst deletions modulate ischemic retinal damage

\section{Abstract}

Ischemia is a primary cause of neuronal death in retinal diseases. The repertoire of expressed transmitter receptors would determine the neurons' responses to ischemic damage, and peptidergic receptors may be involved. With a new in vitro model of the ischemic mouse retina, we investigated whether an altered expression of somatostatin receptors could modulate retinal responses to ischemia. We used retinas of somatostatin receptor 1 ( $\left.\mathrm{sst}_{1}\right)$ knock out $(\mathrm{KO})$ mice, where $\mathrm{sst}_{2}$ are over-expressed and overfunctional, and of $\mathrm{sst}_{2} \mathrm{KO}$ mice. TUNEL analysis of ischemic retinas showed a marked reduction of cell death in $\mathrm{sst}_{1} \mathrm{KO}$ retinas, while there were no differences between wild type (WT) and sst 2 KO retinas. In addition, caspase-3 mRNA expression was also reduced in sst $_{1} \mathrm{KO}$ as compared to WT retinas. An immunohistochemical analysis demonstrated that different cell populations responded differently to the ischemic insult, and that the persistence of some immunohistochemical markers was greater in $\mathrm{sst}_{1} \mathrm{KO}$ than in WT or in $\mathrm{sst}_{2} \mathrm{KO}$ retinas. In particular, rod bipolar cell survival was markedly improved in $\mathrm{sst}_{1} \mathrm{KO}$ retinas, while it was dramatically decreased in $\mathrm{sst}_{2} \mathrm{KO}$ retinas. Furthermore, consistent with a role of glutamate excitotoxicity in ischemia-induced neuronal death, retinal glutamate release was observed to increase under ischemic conditions, but this increase was significantly reduced in $\mathrm{sst}_{1} \mathrm{KO}$ retinas. These observations demonstrate that an increased presence of functional $\mathrm{sst}_{2}$ protects against retinal ischemia, thus implementing the background for the use of sst $_{2}$ analogs in therapies of retinal diseases such as glaucoma or diabetic retinopathy. 
E. Catalani et al.

\section{Introduction}

The primary cause of neuronal death in the diseased retina is ischemia, a condition that can be considered a final common pathway for injury in different retinal pathologies (Osborne et al., 2004). Both excessive glutamate release and apoptotic mechanisms are involved in the process of ischemia-induced neuronal cell death (Won et al., 2002).

A number of in vitro models of the ischemic retina have been developed (Neal et al., 1994; Osborne et al., 1997; Maynard et al., 1998; Quinones-Hinojosa et al., 1999; Tezel \& Wax, 1999; Kuriyama et al., 2001; Luo et al., 2001; Napper et al., 2001; Endo et al., 2002; Tamada et al., 2002; Izumi et al., 2003; Bull \& Barnett, 2004; Payet et al., 2004; Ueda et al., 2004; Kinukawa et al., 2005; Mastrodimou et al., 2005). In these models, different levels of oxygen supply and of glucose availability have been employed. In addition, different animal species ranging from chicks to rats, rabbits or pigs have been used. Notably, no in vitro experimental models of the ischemic mouse retina have been reported, to our knowledge, up to now. The first aim of the present work was to establish an in vitro model of the ischemic mouse retina, providing the evidence of the presence of apoptotic markers, the characterization of cell death in each retinal layer and in selected, immunohistochemically-identified neuronal populations, and the correlation of the ischemic damage with the rate of glutamate release.

Using this model and mice with genetic alterations of the somatostatinergic system, we then aimed at investigating possible actions of the peptide somatostatin (somatotropin release-inhibiting factor, SRIF) in the rescue of retinal cells from ischemic damage. SRIF and its receptor subtypes ( sst $_{1}$ through sst $_{5}$ ) are expressed in the retina (Bagnoli et al., 2003; Thermos, 2003; Casini et al., 2005), where SRIF may influence cell functions and transmitter release (Vasilaki et al., 2002; Mastrodimou \& 
Thermos, 2004; Pavan et al., 2004; Casini et al., 2005; Kouvidi et al., 2006), including glutamate release (Dal Monte et al., 2003a). Interestingly, activation of $\mathrm{sst}_{2}$ receptors by SRIF or its analogs protects retinal neurons against ischemia-induced damage (Celiker \& Ilhan, 2002; Mastrodimou et al., 2005). Transgenic mice with sst $_{1}$ or sst $_{2}$ receptor deletion have been generated (Zheng et al., 1997; Kreienkamp et al., 1999; Allen et al., 2003). In their retinas, $s t_{1}$ and $s_{2} t_{2}$ receptor expressions have been found to compensate for each other. Indeed, $\mathrm{sst}_{1}$ receptor loss causes an increased expression of $\mathrm{sst}_{2}$ receptors, while genetic deletion of the $\mathrm{sst}_{2}$ receptor induces an increased expression of the sst $_{1}$ receptor (Dal Monte et al., 2003b; Casini et al., 2004; Casini et al., 2005). In addition, recent findings indicate that sst $_{2}$ receptor over-expression is correlated with enhanced $\mathrm{sst}_{2}$ receptor function (Bigiani et al., 2004; Pavan et al., 2004). The second aim of the present study was to assess the consequences of ischemic treatment in sst $\mathrm{KO}$ and in $\mathrm{sst}_{2} \mathrm{KO}$ retinas, with the hypothesis that, compared to WT retinas, a chronic over-expression of $\mathrm{sst}_{2}$ receptors (as in $\mathrm{sst}_{1} \mathrm{KO}$ retinas) may reduce the ischemic damage, while the lack of $s s t_{2}$ receptors (as in $s^{2} t_{2} \mathrm{KO}$ retinas) should be associated with heavier damage.

\section{Materials and Methods}

\section{Animals}

Experiments were performed on mouse retinas of WT (C57BL/6) and $\mathrm{sst}_{1}$ or $^{\mathrm{sst}} \mathrm{K}_{2} \mathrm{KO}$ strains (Kreienkamp et al., 1999; Allen et al., 2003) of both sexes. Experiments were performed in compliance with the Italian law on animal care $\mathrm{N}^{\circ} 116 / 1992$ and in accordance with the European Community Council Directive (EEC/609/86). In all experiments, mice were anesthetized by i.p. injection of Avertin (1.2\% tribromoethanol 
and $2.4 \%$ amylene hydrate in distilled water, $0.02 \mathrm{ml} / \mathrm{gm}$ body weight; Sigma) and killed by cervical dislocation. The retinas were rapidly dissected in phosphate-buffered saline (PBS) and subjected to ischemic treatment or incubated in control conditions. They were then used for the terminal-deoxynucleotidyl-transferase-mediated deoxyuridine triphosphate nick end labeling (TUNEL) assays, for the assessment of caspase-3 mRNA expression with semi-quantitative reverse transcription-polymerase chain reaction (RT-PCR), or for immunohistochemical labeling of selected retinal cell populations. Some of the incubation media were used for the determination of glutamate release with high performance liquid chromatography electrospray mass spectrometry (HPLC ESI-MS). All experiments were performed at the same time of the day (between 9.00 and 11.00 a.m.) in order to exclude possible circadian influences. The data were collected from both male and female WT and KO mice; the results were combined since there was no apparent gender difference.

\section{Ischemic treatment}

The dissected retinas were incubated for different periods of time at $37^{\circ} \mathrm{C}$ in $\mathrm{N}_{2-}$ saturated PBS containing different concentrations of iodoacetic acid (IAA; Sigma) in airtight vials (ischemic treatment) or in air-saturated PBS containing $6 \mathrm{mM}$ glucose in open vials (control conditions). Experiments were conducted in order to set the conditions of the ischemic treatment to obtain a minimum and a maximum effect. We defined the "minimum effect" as that of having at least $20 \%$ cell death, determined with an analysis of the TUNEL staining (see below), in all three nuclear layers, i.e. the outer nuclear layer (ONL), the inner nuclear layer (INL) and the ganglion cell layer (GCL). The "maximum effect" was defined as that determining more than $90 \%$ cell death in at 
least one of the nuclear layers. The minimum and the maximum effects were obtained using the same concentration of $250 \mathrm{mM}$ IAA but with different incubation times: the minimum effect was observed after $1 \mathrm{~h}$ incubation, while the maximum effect was observed after $6 \mathrm{~h}$. Data were also collected at $3 \mathrm{~h}$. Control retinas were incubated for corresponding periods in control conditions. In the cases of 3 or $6 \mathrm{~h}$ incubation, both the ischemic and the control solutions were changed every hour.

\section{Preparation of retinal sections}

At the end of the incubation period, the retinas used for the TUNEL or the immunohistochemical stainings were immersion fixed in $4 \%$ paraformaldehyde in 0.1 M phosphate buffer $(\mathrm{PB})$ for $45^{\prime}-60^{\prime}$ at room temperature and stored overnight in $25 \%$ sucrose in $0.1 \mathrm{M} \mathrm{PB}$ at $4^{\circ} \mathrm{C}$. Retinal sections were cut perpendicularly to the vitreal surface at $10 \mu \mathrm{m}$ with a cryostat, mounted onto gelatin-coated slides and stored at $20^{\circ} \mathrm{C}$. All retinas were cut with the same temporal-to-nasal orientation. Consecutive sections were alternately put onto a series of five slides, so that on each slide the sections were spaced every $50 \mu \mathrm{m}$. Five sections were put on each slide, and five series of slides were prepared from each retina. Corresponding series of ischemic and control sections were used in each experiment. Three retinas were analyzed for each experimental condition. At least two series of slides from each retina were used for the TUNEL staining, while the remaining slides were used for immunohistochemistry.

\section{TUNEL staining and quantitative analysis}

An in situ cell death detection kit (Roche Diagnostics) was used to identify apoptotic profiles by TUNEL technique according to the manufacturer's instructions. The slides 
were coverslipped in a $0.1 \mathrm{M}$ PB-glycerin mixture containing $0.5 \mu \mathrm{g} / \mathrm{ml}$ of 4 '-6diamidino-2-phenylindole (DAPI, Sigma).

The fluorescent TUNEL staining was evaluated in selected sections to calculate an index of cell death in the nuclear layers of the retina. The measurements were obtained with a system of computer-assisted image analysis using Zeiss Axiovision 4 and KS300 software. Images of both the TUNEL and the DAPI stainings were acquired with a digital photocamera (Axiocam MRC) connected to a Zeiss microscope equipped with epi-fluorescence. The digital images were optimized for contrast and brightness using Adobe Photoshop (Adobe Systems, Mountain View, CA, USA). For the quantitative analysis, a field about $90 \mu \mathrm{m}$ wide was selected in each image (see figure 1). In the GCL, the index of cell death was calculated as the ratio between the number of the TUNEL-labeled and that of the DAPI-stained cells. In contrast, it was very difficult to count individual TUNEL-positive cells in the ONL and in the INL, and the index of cell death in these layers was calculated as follows: both the DAPI and the TUNEL images relative to the same field were visualized. Using the KS-300 software, the areas of the ONL and of the INL in the DAPI image were measured. Subsequently, the TUNEL image was thresholded and the labeled areas in the ONL and in the INL were measured. The ratio between the area covered by the TUNEL staining and the area of the retinal layer seen with the DAPI counterstain was taken as an index of cell death. In the remainder of the paper and in the figures, the expressions "percentage of cell death" or "\% of cell death" refer equally to the indexes calculated in the GCL and to those calculated in the ONL or INL. 
sst deletions modulate ischemic retinal damage

\section{Caspase-3 semi-quantitative RT-PCR}

The expression of caspase-3 mRNA was evaluated by semi-quantitative RT-PCR in WT and in sst $_{1}$ KO retinas. Total cellular RNA was extracted with the Micro-to-Midi Total RNA Purification System (Invitrogen, Milano, Italy), according to the manufacturer's recommended procedure. cDNA was synthesized from $1 \mu \mathrm{g}$ total RNA using a first strand cDNA synthesis kit (F. Hoffmann-La Roche, Basel, Switzerland). Primer pairs for caspase-3 (Eurobio, Les Ulis, France) were designed to hybridize to unique regions of the respective mouse sequence; forward: AGCAGCTTTGTGTGTGTGATTCTAA; reverse: GTCTGACTGGAAAGCCGAAACT). Cyclophilin B mRNA, whose expression is unchanged in ischemic retinas (Agardh et al., 2006), was used as an internal standard (Cristiani et al., 2002). The PCR reactions were carried out using $1 \mu \mathrm{g}$ of cDNA in a $25 \mu \mathrm{l}$ total volume of PCR buffer (Promega), containing $1.5 \mathrm{mM} \mathrm{MgCl}_{2}$, $2.5 \mathrm{mM} \mathrm{dNTP}$, and $0.75 \mu \mathrm{M}$ of appropriate primers and Taq polymerase (1.2 $\mathrm{U}$, Promega). The amplification reaction was carried out in a Bio-Rad thermocycler for 35 cycles. A $25 \mu 1$ sample of the PCR reaction was electrophoresed on a 3\% agarose gel using the Bio-Rad Sub-cell GT system and stained with BMA GelStar (Rockland, ME, USA). After migration, bands corresponding to the amplified products were analyzed with Gel Doc 2000 System equipped with Quantity One software (Bio-Rad). Semiquantitative analysis of the caspase-3 PCR products was performed by measuring the optical density of the bands corresponding to caspase- 3 mRNA normalized to the optical density of the band corresponding to the respective cyclophilin B mRNA. 


\section{E. Catalani et al.}

\section{Immunohistochemistry}

The set of primary antibodies used in these studies was designed to label neuronal populations among photoreceptors, bipolar cells, amacrine cells and ganglion cells. In particular, antibodies to cone arrestin (1:500) were employed to label cone photoreceptors; calbindin (1:2000) for horizontal cells; the calcium binding protein CaBP5 (1:500) and the MAb115A10 antibody (1:3000) for multiple types of bipolar cells; the G protein $\mathrm{G} \gamma 13$ (1:1000) for populations of ON-bipolar cells; protein kinase C (PKC, 1:200) for rod bipolar cells; GABA transporter-1 (GAT-1, 1:200), choline acetyltransferase (ChAT, 1:50), tyrosine hydroxylase (TH, 1:400) and SRIF (1:100) for different populations of amacrine cells; $\beta$-Tubulin (1:400) for ganglion cells. In addition, antibodies to the $\mathrm{sst}_{2 \mathrm{~A}}$ receptor were also employed. The slides were air dried before immunohistochemical procedures. Then, the sections were washed in $0.1 \mathrm{M} \mathrm{PB}$ and incubated overnight at $4{ }^{\circ} \mathrm{C}$ in each one of the primary antibodies diluted in $0.1 \mathrm{M}$ PB containing $0.5 \%$ Triton X-100. Following washes in $0.1 \mathrm{M} \mathrm{PB}$, the sections were incubated with the appropriate secondary antibody conjugated with Alexa Fluor 488 (Molecular Probes) at a dilution of 1:200 in 0.1 M PB containing 0.5\% Triton X-100 for $1 \mathrm{~h}$ at room temperature. Finally, the slides were coverslipped in a $0.1 \mathrm{M}$ PB-glycerin mixture containing $0.5 \mu \mathrm{g} / \mathrm{ml}$ DAPI.

An estimation of the differences in immunostaining patterns among the different experimental groups was coded in tables 2-4 with a scale of "+" and "-", with "+++" indicating a picture similar to that of controls, "++" indicating a slight but evident reduction of immunofluorescence intensity and/or of immunostained cell parts (processes or somata), “+” indicating a dramatic decrease of immunostaining intensity and of immunostained structures, "+/-" indicating the occurrence of only limited 
sst deletions modulate ischemic retinal damage

amounts of immunofluorescent material, "-" indicating the absence of any detectable immunofluorescence.

\section{HPLC ESI-MS}

The rate of glutamate release was measured using HPLC ESI-MS in WT and in sst1 KO retinas. At the end of the incubation period, the vials containing the ischemic and the control solutions were stored at $-80^{\circ} \mathrm{C}$. Glutamate levels were determined according to Li et al. (2005), with some modifications. Briefly, the samples were lyophilized and reconstituted in $100 \mu \mathrm{l}$ of $10 \%$ acetonitrile (Carlo Erba, Milan, Italy). For chemical derivatization, they were incubated for $30 \mathrm{~min}$ in darkness at $60^{\circ} \mathrm{C}$ in a water bath with $20 \mu \mathrm{l}$ of $10 \mathrm{M} \mathrm{KOH}$ and $500 \mu \mathrm{l}$ of 10-4 M dansyl chloride (Sigma). HPLC was performed using a Beckman Model 126 Programming Solvent Module pump chromatograph (Beckman Instruments, Brea, CA). The chromatographic separations were carried out with Waters ODS2 Spherisorb $250 \mathrm{~mm}$ x $4.6 \mathrm{~mm}$ I.D. $5 \mu \mathrm{m}$ packed column (Teknokroma, Barcelona, Spain) as stationary phase, preceded by a guard column of Spherisorb RPC18, $5 \mu \mathrm{m}, 4 \mathrm{~mm} \times 4 \mathrm{~mm}$. The mobile phase was DD water $0.5 \%(\mathrm{vlv})$ formic acid (mobile phase A), and acetonitrile $0.5 \%(\mathrm{v} / \mathrm{v}$ ) formic acid (mobile phase B). ESI-MS was performed on an ion trap mass spectrometer (Esquire 3000 plus, Bruker Daltonik, Bremen, Germany) in the positive mode. For the analysis with pneumatically assisted ESI, an electrospray voltage of $4 \mathrm{kV}$ and a Nebulizer 35 psi and Dry Gas $10 \mathrm{~L} / \mathrm{min}$ were employed. The temperature of dry gas was set to $300{ }^{\circ} \mathrm{C}$. Full-scan spectra were acquired over the range m/z 50-1500 (scan duration, $1 \mathrm{sec}$.). 
E. Catalani et al.

\section{Statistics}

In the TUNEL, RT-PCR and HPLC studies, the comparisons of the data were performed using ANOVA and Tukey's multiple comparison post test upon verification of normal distribution. When specified, statistical significance was also evaluated using paired Student's $t$-test. The software GraphPad Prism (Graph Software, San Diego, CA, USA) was used. $p<0.05$ was considered statistically significant. In all cases, the results are expressed as means \pm S.E.M.

\section{Figure preparation}

Both the TUNEL and the immunofluorescence images were acquired using a 40x planNEOFLUAR Zeiss objective, the Axiocam photocamera and the Zeiss Axiovision 4 software. The digital images were sized and optimized for contrast and brightness using Adobe Photoshop. Final images were saved at a minimum of 300 dpi.

\section{Results}

\section{TUNEL staining}

In WT retinas incubated in control conditions, TUNEL labeling was not detected after 1h, 3h or $6 \mathrm{~h}$ incubation (Fig. 1F, left). The presence of apoptotic signs, instead, was evident in retinas incubated in the ischemic solution. Pyknotic nuclei, interpreted as apoptotic cells, could be detected in the DAPI images after $1 \mathrm{~h}$ ischemic treatment (Fig. 1A, left). This picture corresponded to the presence of a certain TUNEL labeling in the ONL, INL and GCL (Fig. 1A, center). In particular, in the thresholded TUNEL images (Fig. 1A, right), the ONL was apparently the retinal layer with the highest amount of staining, while a more scattered labeling could be seen in the INL. In the GCL, sparse 
sst deletions modulate ischemic retinal damage

somata displayed TUNEL positivity. After $3 \mathrm{~h}$ of ischemic treatment (Fig. 1B), more pyknotic nuclei were seen with the DAPI staining, and a larger spread of TUNEL labeling was observed in the ONL and in the INL. In the GCL, virtually all cell bodies were TUNEL-positive. In the $6 \mathrm{~h}$ treated retinas (Fig. 1C), both the number of pyknotic, DAPI-stained nuclei and the amount of the TUNEL labeling had further increased in the ONL and in the INL.

The quantitative analysis of the TUNEL-labeled retinal sections confirmed that the $1 \mathrm{~h}$ ischemic treatment resulted in the "minimum effect", with at least $20 \%$ cell death in each nuclear layer (see methods). In particular, cell death in the ONL was around 35\%, in the INL slightly above $20 \%$ and in the GCL around $30 \%$ (Fig. 2A). The percentage of cell death significantly increased in all nuclear layers after $3 \mathrm{~h}$ ischemic treatment, with values in the GCL approaching 90\%. The 90\% value was exceeded ("maximum effect") both in the ONL and in the GCL after $6 \mathrm{~h}$ ischemia. Although the percentage of cell death appeared to be increased in all nuclear layers, a statistically significant increment with respect to the $3 \mathrm{~h}$ treatment was only observed in the ONL.

The percentages of cell death were also compared in WT, sst ${ }_{1} \mathrm{KO}$ and $\mathrm{sst}_{2} \mathrm{KO}$ ischemic retinas. Similar to WT retinas, TUNEL staining was not detected in $\mathrm{sst}_{1} \mathrm{KO}$ or in $\mathrm{sst}_{2} \mathrm{KO}$ retinas incubated in control conditions for $1 \mathrm{~h}, 3 \mathrm{~h}$ or $6 \mathrm{~h}$ (Fig. 1F, center and right). Figure $1 \mathrm{D}$ and $1 \mathrm{E}$ shows the DAPI staining, the TUNEL labeling and the thresholded TUNEL image in $\mathrm{sst}_{1} \mathrm{KO}$ and in $\mathrm{sst}_{2} \mathrm{KO}$ retinas, respectively, incubated for $1 \mathrm{~h}$ in ischemic conditions. It is apparent that the TUNEL labeling was more restricted in the $\mathrm{sst}_{1} \mathrm{KO}$ retinas than in the $\mathrm{WT}$ or in the $\mathrm{sst}_{2} \mathrm{KO}$ retinas. The quantitative analysis (Fig. 2B) confirmed that, after $1 \mathrm{~h}$ ischemia, the percentage of cell death in the ONL, INL and GCL was significantly lower in $\mathrm{sst}_{1} \mathrm{KO}$ retinas than in the corresponding 
layers of WT or $\mathrm{sst}_{2} \mathrm{KO}$ retinas. In particular, comparing WT with $\mathrm{sst}_{1} \mathrm{KO}$ retinas, cell death in the ONL diminished from $35 \%$ to $17 \%$, in the INL from $21 \%$ to $5 \%$, and in the GCL from $28 \%$ to $9 \%$. No differences were recorded between WT and $\mathrm{sst}_{2} \mathrm{KO}$ retinas. After $3 \mathrm{~h}$ ischemia, significant differences between $\mathrm{sst}_{1} \mathrm{KO}$ and $\mathrm{WT}$ or $\mathrm{sst}_{2} \mathrm{KO}$ retinas were no longer detected, and the percentages of cell death in $\mathrm{sst}_{1} \mathrm{KO}$ retinas became similar to those in WT retinas (inset of figure 2B).

\section{Caspase-3 expression}

As shown in figure 3A, RT-PCR yielded amplification at $136 \mathrm{bp}$, which was the expected molecular weight of caspase- 3 mRNA products. In samples from WT retinas incubated for $1 \mathrm{~h}, 3 \mathrm{~h}$ or $6 \mathrm{~h}$ in control conditions, similar levels of caspase- 3 mRNA expression were observed. In contrast, expression levels were significantly increased in 1h ischemic retinas (around 30\% higher compared to controls), while they were significantly reduced after $3 \mathrm{~h}$ of ischemic treatment and absent after 6h (Fig. 3A-B). According to other studies of ischemic retinas (Agardh et al., 2006), the levels of cyclophilin-B mRNA, used as an internal standard, were similar both in controls and in ischemic retinas.

To assess whether the apparent, although partial, protection from cell death in $\mathrm{sst}_{1}$ KO retinas, as evaluated with the TUNEL staining, was accompanied by any changes in other apoptotic markers, caspase-3 expression was investigated with semi-quantitative RT-PCR in WT and in sst ${ }_{1} \mathrm{KO}$ retinas after $1 \mathrm{~h}$ ischemia. Both in WT and in $\mathrm{sst}_{1} \mathrm{KO}$ retinas, amplification products were detected at 136 bp (caspase-3, Fig. 3C). Semiquantitative evaluations of the amplified products showed a highly significant reduction 
sst deletions modulate ischemic retinal damage

(around 65\%) of caspase-3 mRNA expression in $\mathrm{sst}_{1} \mathrm{KO}$ retinas compared to WT retinas (Fig. 3D).

\section{Immunohistochemistry}

The immunohistochemical labelings of WT retinas incubated in control conditions did not differ from those of normal, untreated retinas. In contrast, there was a high degree of heterogeneity in the responses of the different cell populations to the ischemic insult. Indeed, the different immunohistochemical markers could be grouped into four classes according to their persistence in the WT ischemic retinas: i) markers whose expression patterns persisted unaltered in ischemic retinas up to $6 \mathrm{~h}$; ii) markers which displayed changes in response to ischemia at $1 \mathrm{~h}, 3 \mathrm{~h}$ and $6 \mathrm{~h}$; iii) markers which were severely reduced and disappeared after $3 \mathrm{~h}$ or $6 \mathrm{~h}$ ischemia; iv) markers which could not be detected in ischemic retinas after $1 \mathrm{~h}$ treatment.

Class (i) included cone arrestin and GAT-1. Cone photoreceptors were labeled by antibodies directed to cone arrestin in control retinas and in ischemic retinas up to $6 \mathrm{~h}$ without apparent changes in the immunolabeling pattern, the label intensity or the number of immunopositive cone photoreceptors (Fig. 4A). Similarly, the GAT-1 immunostaining (Fig. 4B) was basically unchanged in control and in ischemic retinas. A possible decrease in the intensity of GAT-1 immunostaining in the inner plexiform layer (IPL) after $6 \mathrm{~h}$ ischemia was not consistently observed in all the samples examined.

Class (ii) included $\beta$-Tubulin, TH and PKC. As shown in figure 4C, $\beta$-Tubulin immunopositive ganglion cells and processes in the IPL could be observed in control as well as in ischemic retinas. The ischemic treatment did not influence the occurrence of immunolabeled somata in the GCL, but determined a consistent decrease of the density 
of $\beta$-Tubulin containing fibers in the IPL. The TH immunostaining (Fig. 4D) was characterized by sparsely distributed somata in the proximal INL and a rich bundle of varicose fibers in the distal IPL in control retinas. In addition, TH-immunopositive processes were also in the middle IPL and in the INL directed towards the outer plexiform layer (OPL, arrows in fig. 4D). After $1 \mathrm{~h}$ or $3 \mathrm{~h}$ ischemic treatment, brightly immunostained cell bodies were still present, however the processes in the distal IPL had lost their varicosities and the fibers in the middle IPL or in the INL/OPL were no longer observed. After $6 \mathrm{~h}$ ischemic treatment, the TH-immunostained fiber bundle in the IPL was severely reduced, although immunoreactive somata could still be observed. PKC immunoreactivity identified the population of rod bipolar cells (Fig. 4E). After $1 \mathrm{~h}$ ischemic treatment, the immunofluorescence intensity was reduced and a lower number of immunolabeled somata were visible, although there were no apparent variations in the density of PKC-immunoreactive rod bipolar cell axons or axon terminals in the IPL. A feature that was consistently observed in the $1 \mathrm{~h}$ ischemic retinas was the swelling of the distal segment of rod bipolar cell axons (arrows in Fig. 4E). After $3 \mathrm{~h}$ and $6 \mathrm{~h}$ ischemic treatment, PKC immunostaining in rod bipolar cell dendrites, somata and axons was further decreased. The PKC-immunoreactive axonal terminals in the IPL remained visible, and they appeared to be larger than in control retinas.

Class (iii) included the G protein G $\gamma 13$ and SRIF. Numerous ON-bipolar cells were visualized by G $\gamma 13$ immunoreactivity (Fig. 4F). After $1 \mathrm{~h}$ ischemia, the distal portion of these cells still displayed G $\gamma 13$-immunostaining, while bipolar cell axons and terminals were faintly labeled. After $3 \mathrm{~h}$ ischemia, only a band of immunostaining was left in the OPL, and after $6 \mathrm{~h}$ ischemia G $\gamma 13$ immunoreactivity could not be detected. SRIFcontaining amacrine cells (Fig. 4G) were very sparsely distributed, and varicose SRIF- 
sst deletions modulate ischemic retinal damage

immunostained processes were mainly seen in distal IPL of control retinas. After $1 \mathrm{~h}$ ischemic treatment, SRIF-immunopositive somata were not detected, and only a few immunolabeled fibers could be observed in the IPL. Longer ischemic treatments completely abolished SRIF immunoreactivity.

Class (iv) included calbindin, MAb115A10, CaBP5 and ChAT. While these markers were easily observed in the appropriate cell types in retinas incubated in control conditions, none of them were detectable by immunohistochemistry in retinas subjected to $1 \mathrm{~h}$ ischemic treatment (not shown).

After this immunohistochemical characterization of the effects of the ischemic treatment in WT retinas, we tested whether selected populations of retinal neurons were differentially affected by the ischemic treatment in $\mathrm{sst}_{1} \mathrm{KO}$ and/or in $\mathrm{sst}_{2} \mathrm{KO}$ retinas. The results are summarized in Tables 1 and 2. Appreciable and consistent differences were observed in the immunostaining patterns of $\mathrm{TH}$ and of three different bipolar cell markers, namely PKC, MAb115A10 and CaBP5. Such differences were not observed in the immunostaining patterns of the other markers listed in table 1. TH and PKC belong to the "class (ii)" markers, while MAb115A10 and CaBP5 belong to "class (iv)".

Figure 5 shows that the TH immunostaining was preserved without notable changes at least up to $3 \mathrm{~h}$ ischemic treatment in $\mathrm{sst}_{1} \mathrm{KO}$ as well as in $\mathrm{sst}_{2} \mathrm{KO}$ retinas (see also Tab. 1 and 2). Indeed, while in WT retinas there was a prominent decrease of varicose, TH-immunoreactive processes (Fig. 5A), a pattern of TH-containing fibers similar to the control was observed in sst ${ }_{1} \mathrm{KO}$ (Fig. 5B) and in sst ${ }_{2} \mathrm{KO}$ (Fig. 5C) retinas. A similar pattern was also maintained after $6 \mathrm{~h}$ ischemia (Tab. 2).

With respect to PKC-immunolabeled rod bipolar cells of WT retinas (Fig. 6A), those of sst $_{1} \mathrm{KO}$ retinas appeared less susceptible to ischemic damage after both $1 \mathrm{~h}$ and 
3h ischemic treatment (Fig. 6B, Tab. 1 and 2). Indeed, after $1 \mathrm{~h}$ ischemia rod bipolar cells of sst $_{1} \mathrm{KO}$ retinas did not display the swelling of their distal axons, which was instead a characteristic of rod bipolar cells in the $1 \mathrm{~h}$ ischemic WT retina. In addition, both after $1 \mathrm{~h}$ and $3 \mathrm{~h}$ ischemia, the intensity of $\mathrm{PKC}$ immunostaining was considerably stronger in $\mathrm{sst}_{1} \mathrm{KO}$ than in WT retinas. In $\mathrm{sst}_{2} \mathrm{KO}$ retinas (Fig. 6C), the PKC immunoreactive pattern in control conditions was similar to that of WT and $\mathrm{sst}_{1} \mathrm{KO}$ retinas in the same conditions. However, after $1 \mathrm{~h}$ or $3 \mathrm{~h}$ ischemia the PKC immunostaining in $\mathrm{sst}_{2} \mathrm{KO}$ retinas was barely detectable and dramatically less intense than in $\mathrm{WT}$ and in $\mathrm{sst}_{1} \mathrm{KO}$ retinas. After $6 \mathrm{~h}$ ischemia, $\mathrm{sst}_{1} \mathrm{KO}$ retinas still displayed stronger PKC immunoreactivity than WT retinas, while immunostaining was not detected in $\mathrm{sst}_{2} \mathrm{KO}$ retinas (Tab. 2).

Similar to WT retinas, MAb115A10 immunoreactivity disappeared after $1 \mathrm{~h}$ ischemia in sst $_{2} \mathrm{KO}$ retinas. In contrast, some weak immunostaining was still visible in the OPL of $1 \mathrm{~h}$ ischemic $\mathrm{sst}_{1} \mathrm{KO}$ retinas, where dendrites of MAb115A10-expressing bipolar cells could be detected (not shown). No immunolabeling was observed in bipolar cell somata, axons or axonal terminals in the IPL. After $3 \mathrm{~h}$ or $6 \mathrm{~h}$ ischemia, MAb115A10 immunoreactivity was completely absent in all the retinas analyzed.

Similar to MAb115A10, also CaBP5 immunoreactivity was absent in WT (Fig. 7A) and in $\mathrm{sst}_{2} \mathrm{KO}(\mathrm{Fig} .7 \mathrm{C})$ retinas after $1 \mathrm{~h}$ or $3 \mathrm{~h}$ ischemia. In $1 \mathrm{~h}$ ischemic $\mathrm{sst}_{1} \mathrm{KO}$ retinas (Fig. 7B and Tab. 1), instead, strong CaBP5 immunostaining could be observed in dendrites, somata, axons and axon terminals of numerous bipolar cells. After $3 \mathrm{~h}$ ischemia, immunofluorescent bipolar cell dendrites, somata and axonal terminals were still visible in $\mathrm{sst}_{1} \mathrm{KO}$ retinas (Fig. $7 \mathrm{~B}$ and Tab. 2). After $6 \mathrm{~h}$ ischemia, some immunolabeling could still be detected in $\mathrm{sst}_{1} \mathrm{KO}$ retinas (Tab. 2). 
The immunostaining patterns of the $\mathrm{sst}_{2 \mathrm{~A}}$ receptor were investigated to ascertain whether $\mathrm{sst}_{2}$ receptors were still present in $\mathrm{WT}$ and/or $\mathrm{sst}_{1} \mathrm{KO}$ retinas after ischemic treatment. In both WT and $\mathrm{sst}_{1} \mathrm{KO}$ control retinas, these patterns were consistent with those described previously (Cristiani et al., 2002; Casini et al., 2004), with sst $_{2 \mathrm{~A}}$ immunoreactivity localized to, mainly, amacrine cells and rod bipolar cells. After $1 \mathrm{~h}$ ischemia, while sst ${ }_{2 \mathrm{~A}}$ immunofluorescence was not affected in the amacrine cells, it was reduced in the rod bipolar cells (not shown). This reduction was less pronounced in $\mathrm{sst}_{1}$ $\mathrm{KO}$ than in WT retinas, consistent with the PKC immunostaining in ischemic retinas described above.

\section{Glutamate release}

In WT retinas incubated in control conditions, measured glutamate release was $0.29 \pm 0.04 \mu \mathrm{g} / \mathrm{ml}$ after $1 \mathrm{~h}, 0.39 \pm 0.03 \mu \mathrm{g} / \mathrm{ml}$ after $3 \mathrm{~h}$, and $0.43 \pm 0.02 \mu \mathrm{g} / \mathrm{ml}$ after $6 \mathrm{~h}$. There were no significant differences between these values, and they were in the range of previously reported measurements of glutamate release in the mouse retina (Dal Monte et al., 2003a). A three-fold increase of glutamate release was observed in $1 \mathrm{~h}$ ischemic retinas, and further increases were detected after $3 \mathrm{~h}$ and after $6 \mathrm{~h}$ incubation in ischemic conditions (Fig. 8A).

To assess whether the apparent reduced susceptibility of $\mathrm{sst}_{1} \mathrm{KO}$ retinas to the ischemic treatment was concomitant with differences in the rate of glutamate release, this release was evaluated in WT and in $\mathrm{sst}_{1} \mathrm{KO}$ retinas after $1 \mathrm{~h}$ or $3 \mathrm{~h}$ incubation in control or in ischemic conditions. Comparable values were recorded in WT and in $\mathrm{sst}_{1}$ $\mathrm{KO}$ retinas incubated in control conditions both after $1 \mathrm{~h}$ and after $3 \mathrm{~h}$. In contrast, as shown in figure $8 \mathrm{~B}$, there were differences in the ischemic retinas. Indeed, after $1 \mathrm{~h}$ or 
E. Catalani et al.

$3 \mathrm{~h}$ ischemic treatment, the rate of glutamate release in $\mathrm{sst}_{1} \mathrm{KO}$ retinas was significantly reduced compared to that in WT retinas.

\section{Discussion}

\section{In vitro ischemic model of the mouse retina}

In the present work, we have established a reliable in vitro model of the ischemic mouse retina. This model, and its possible variants, may prove useful for investigations of the retinas of transgenic mice in relation to their responses to ischemic conditions, as we did in this study.

\section{Apoptosis}

The presence of TUNEL labeling in ischemic retinas and the increase of caspase- 3 mRNA expression after $1 \mathrm{~h}$ ischemia suggest that retinal cells in our ischemic in vitro model die by apoptotic mechanisms. Indeed, in the retina, it has been shown that ischemia-induced apoptosis is executed at least in part by caspase-3, which is likely to preferentially act in the INL and GCL, an that preventing caspase activation protects against ischemia-induced retinal damage (Katai \& Yoshimura, 1999).

We have observed an increased caspase-3 mRNA expression after $1 \mathrm{~h}$ ischemic treatment, followed by a decrease. This observation is consistent with observations in in vivo retinal models of ischemia-reperfusion or permanently increased intraocular pressure, reporting peaks of caspase-3 expression in the early phases of the apoptotic process (Yamamoto et al., 2006).

In in vitro models of retinal ischemia, both TUNEL labeling and the activation of caspase-3 have been reported in E1A.NR3 retinal cell line exposed to ischemic 
sst deletions modulate ischemic retinal damage

treatment (Tezel \& Wax, 1999), and TUNEL staining has also been evaluated in rat eyecup preparations treated for chemical ischemia (Mastrodimou et al., 2005). Mastrodimou and colleagues (Mastrodimou et al., 2005) reported elevated TUNEL staining and almost complete disappearance of ChAT immunostaining in rat retinas after $6 \mathrm{~h}$ incubation in control conditions. In contrast, in mouse retinas, we have noticed absence of TUNEL staining and permanence of unaltered immunolabelings (including ChAT immunolabeling) up to $6 \mathrm{~h}$ incubation in PBS. The reduced survival during incubation in control conditions of the rat retina compared to the mouse retina can be explained with intrinsic species differences and/or with different sample preparations (rat eyecups vs. mouse dissected retinas).

\section{Immunohistochemical markers}

Several different immunohistochemical markers of retinal cell populations have been investigated in the present study to characterize the in vitro ischemic mouse retina. In an in vitro model of the rat retina, ChAT, TH, $\mathrm{PKC}$ and brain nitric oxide synthase immunoreactivities disappear after incubation in ischemic conditions (Mastrodimou et al., 2005). Instead, in our model of the mouse retina, of these markers, only ChAT is absent in ischemic retinas, while $\mathrm{TH}$ and $\mathrm{PKC}$ immunolabelings persist, at least to a certain extent, in the presence of ischemic treatment. These discrepancies may be explained with the different composition of the ischemic solution, which, in the study of Mastrdimou and colleagues (2005), in addition to IAA also contained $\mathrm{NaCN}$, a potent inhibitor of the respiratory chain.

We found that different immunohistochemical markers are differentially affected by ischemia in our model. Similar observations have been reported for markers of 
E. Catalani et al.

amacrine cell populations in an ischemia-reperfusion model of the rat retina both at the level of mRNA expression and at the level of immunohistochemical localization (Dijk \& Kamphuis, 2004; Dijk et al., 2004). In addition, retinal ischemia in the rat induced by bilateral common carotid artery occlusion differentially affects immunohistochemical markers for different retinal cell populations (Yamamoto et al., 2006).

The partial resistance to ischemic damage of some neuronal types may depend on the quantity and type of glutamate receptors that they express. It is interesting to note that, although dopaminergic amacrine cells are responsive to glutamate, the density of AMPA type glutamate receptors is lower in TH-containing neurons than in other amacrine or ganglion cells (Gabriel et al., 2002). In addition, although the majority of retinal neurons are activated by glutamate agonists at ionotropic receptors, ON-bipolar cells (which include the PKC-containing rod bipolar cells and the G $\gamma 13$-expressing bipolar cells) are not responsive to these agonists, also in accordance to localization studies demonstrating scarce expression of ionotropic glutamate receptors in these cells (Sun \& Kalloniatis, 2006).

\section{Glutamate release}

The data of glutamate release are in line with the hypothesis that one cause of cell death following an ischemic insult is excitotoxicity. Indeed, glutamate levels in the incubation medium have been found to increase in parallel with the intensity of the ischemic treatment. Interestingly, a correlation between caspase-3 and glutamate has been previously noted in dying neurons of the central nervous system. In particular, glutamate-induced apoptosis of cerebrocortical and cerebellar granule neurons appears to be mediated by activation of caspase-3 (Du et al., 1997; Tenneti \& Lipton, 2000). 
sst deletions modulate ischemic retinal damage

\section{Studies with $\mathrm{sst}_{1} \mathrm{KO}$ and $\mathrm{sst}_{2} \mathrm{KO}$ retinas}

\section{Preliminary considerations: are the experimental data fully consistent with the}

\section{hypotheses?}

Our hypothesis was that overexpression of $\mathrm{sst}_{2}$ receptors, as in $\mathrm{sst}_{1} \mathrm{KO}$ retinas, would confer protection against ischemia and that, on the other hand, lack of $\mathrm{sst}_{2}$ receptors, as in $\mathrm{sst}_{2} \mathrm{KO}$ retinas, would worsen the ischemic damage. The experimental data demonstrate that, indeed, sst $_{1} \mathrm{KO}$ retinas are to some extent protected from ischemia and that the loss of $\mathrm{sst}_{2}$ receptors after ischemic treatment is less severe in sst $1 \mathrm{KO}$ than in WT retinas. In contrast, the more serious effects that were expected in $\mathrm{sst}_{2} \mathrm{KO}$ retinas were not detected, but the consequences of the ischemic treatment in these retinas were unexpectedly variegated. Indeed, although most cells in these retinas displayed ischemic damages similar to those in WT retinas, the dopaminergic amacrine cells appeared to be totally spared by ischemia, as in the $\mathrm{sst}_{1} \mathrm{KO}$ retina. The opposite was instead observed in the population of rod bipolar cells, which in $\mathrm{sst}_{2} \mathrm{KO}$ retinas resulted much more damaged by ischemia than in WT retinas.

The mechanism by which overexpression of $\mathrm{sst}_{2}$ receptors results in protection from the ischemic damage is likely to involve $s_{2} t_{2}$-mediated reduction of glutamate release. Indeed, we observed a significant reduction of glutamate release in $\mathrm{sst}_{1} \mathrm{KO}$ retinas compared to WT retinas after ischemic treatment. However, if on the one hand the reduced cell death in $\mathrm{sst}_{1} \mathrm{KO}$ retinas, as evaluated with TUNEL analysis, is likely to be correlated with reduced glutamate release after $1 \mathrm{~h}$ ischemia, on the other hand this correlation is no longer apparent after $3 \mathrm{~h}$ ischemia, when glutamate release in $\mathrm{sst}_{1} \mathrm{KO}$ 
E. Catalani et al.

retinas is still significantly lower than in WT retinas but the percentage of cell death is similar.

In summary, our observations are consistent with the hypothesis that the protection from ischemic damage in $\mathrm{sst}_{1} \mathrm{KO}$ retinas is due to enhanced $\mathrm{sst}_{2}$ receptor expression and function in these retinas (Dal Monte et al., 2003b; Bigiani et al., 2004; Pavan et al., 2004; Casini et al., 2005). This conclusion is also supported by previous data reporting that ischemia-induced retinal damage can be prevented by administration of $\mathrm{sst}_{2}$ receptor-specific agonists (Celiker \& Ilhan, 2002; Mastrodimou et al., 2005). However, the data obtained in our experimental model indicate that a higher level of complexity than the one evidenced by these previous studies must be present within the mechanisms linking sst $_{2}$ receptor functional actions, glutamate release and apoptosis in the control of neuronal survival in the ischemic retina, and further studies will be necessary to elucidate these issues.

\section{Mechanisms of protection from ischemia in sst $\underline{1} \underline{K O}$ retinas}

Retinal cells in the $\mathrm{sst}_{1} \mathrm{KO}$ retina may be protected from ischemia by virtue of two different mechanisms. The first one is ultimately concerned with the rate of glutamate release, whose increase in ischemia is likely to be responsible of neuronal deaths (Osborne et al., 2004). In ischemic conditions, glutamate release would be less enhanced in $\mathrm{sst}_{1} \mathrm{KO}$ than in WT retinas, and the neuronal damage by excitotoxicity would be reduced. This hypothesis is strongly supported by the observation that glutamate release in $\mathrm{sst}_{1} \mathrm{KO}$ ischemic retinas is significantly reduced with respect to WT ischemic retinas. In addition, SRIF acting at $\mathrm{sst}_{2}$ receptors has been reported to reduce glutamate release in the retina (Dal Monte et al., 2003a), and this action is 
amplified in sst $_{1} \mathrm{KO}$ retinas (Bigiani et al., 2004). Although this mechanism is consistent with the survival of a significant quantity of neurons in all nuclear layers, as determined with the TUNEL analysis, it does not explain why large populations of cells such as horizontal cells and ganglion cells, that are activated by glutamate agonists at ionotropic receptors (Sun \& Kalloniatis, 2006), are not spared in sst $_{1} \mathrm{KO}$ retinas. Instead, the main improvement in cell survival is seen, with immunohistochemistry, in rod bipolar cells, which do not respond to ionotropic glutamate receptor agonists (Sun \& Kalloniatis, 2006), and in dopaminergic amacrine cells, which display relatively low concentration of glutamate receptors (Gabriel et al., 2002). The second mechanism is concerned with some positive action that may be exerted by SRIF directly on the cells expressing $\mathrm{sst}_{2}$ receptors. In $\mathrm{sst}_{1} \mathrm{KO}$ retinas, this action would be stronger than in WT or in $\mathrm{sst}_{2} \mathrm{KO}$ retinas, and it would explain why survival is improved in cell populations that express high levels of $\mathrm{sst}_{2}$ receptors, namely the rod bipolar cells and the dopaminergic amacrine cells (Cristiani et al., 2002). It would also explain the observation that the ischemic damage suffered by rod bipolar cells in $\mathrm{sst}_{2} \mathrm{KO}$ retinas, where this "beneficial action" would be totally absent, is more severe than in WT retinas. However, this mechanism would not be totally consistent with the observed lack of enhanced survival in $\mathrm{sst}_{1} \mathrm{KO}$ retinas of other populations of retinal cells expressing $\mathrm{sst}_{2}$ receptors, such as, for instance, the calbindin-containing horizontal cells (Cristiani et al., 2002). We may propose that cell survival in $\mathrm{sst}_{1} \mathrm{KO}$ ischemic retinas depends on both mechanisms, and it is promoted in those cells that over-express the sst $_{2}$ receptors and that, at the same time, can sustain the excitotoxic stress which, although reduced by virtue of $s s t_{2}$-mediated inhibition of glutamate release, is likely to still affect the retina in ischemic conditions. 
E. Catalani et al.

\section{Conclusions}

We have set up a novel in vitro model of the ischemic mouse retina that may prove useful for investigations using transgenic animals. In this model, we have provided evidence that: i) an increased presence of functional $\mathrm{sst}_{2}$ receptors, as in $\mathrm{sst}_{1} \mathrm{KO}$ retinas, protects against ischemic damage, thus confirming and expanding the notion that SRIF analogs acting at the $\mathrm{sst}_{2}$ receptor could represent valid therapeutic agents in degenerative retinal diseases such as glaucoma or diabetic retinopathy; ii) the mechanisms by which neuronal death is retarded in ischemic sst $_{1} \mathrm{KO}$ retinas likely includes both a sst ${ }_{2}$ receptor-mediated inhibition of excess glutamate release and a sst $2_{2}^{-}$ mediated protective action directly in the neurons expressing these receptors; iii) the susceptibility of retinal neurons to ischemia depends not only on the type and the quantity of excitatory and inhibitory inputs mediated by glutamate and GABA receptors, but also on the type and the quantity of receptors responding to a wide range of neuroactive substances, including, for instance, neuropeptides. 
sst deletions modulate ischemic retinal damage

\section{Acknowledgements}

We wish to thank Dr. Cheryl M. Craft, of the Mary D. Allen Laboratory in Vision research, Doheny Eye Institute, Los Angeles, CA, for cone arrestin antibody; Dr. Shinobu C. Fujita, of the Mitsubishi Kagaku Institute of Life Sciences, Tokyo, Japan, for MAb115A10 antibody; Dr. Francoise Haeseleer, of the University of Washington, Seattle, WA, for CaBP5 antibody; Dr. Robert F. Margolskee, of the Mount Sinai School of Medicine, New York, NY, for G $\gamma 13$ antibody. We also thank Dr. Cristiano Papeschi for animal care at the Tuscia University and Gino Bertolini for assistance with the mouse colonies at the University of Pisa. This work was supported by the Italian Ministry of University and Research (MUR, PRIN, grant \# 2005052312). 
E. Catalani et al.

\section{Abbreviations}

CaBP5, calcium binding protein 5; ChAT, choline acetyltransferase; DAPI, 4'-6diamidino-2-phenylindole; GAT-1, $\gamma$-aminobutyric acid transporter-1; GCL, ganglion cell layer; HPLC ESI-MS, high performance liquid chromatography electrospray mass spectrometry; IAA, iodoacetic acid; INL, inner nuclear layer; IPL, inner plexiform layer; KO, knock out; ONL, outer nuclear layer; OPL, outer plexiform layer; PB, phosphate buffer; PBS, phosphate-buffered saline; PKC, protein kinase C; RT-PCR, reverse transcription-polymerase chain reaction; S.E.M., standard error of the mean; SRIF, somatostatin; $\mathrm{sst}_{1}$, somatostatin receptor subtype 1 ; $\mathrm{sst}_{2}$, somatostatin receptor subtype 2; TH, tyrosine hydroxylase; TUNEL, terminal-deoxynucleotidyl-transferasemediated deoxyuridine triphosphate nick end labeling; WT, wild type. 
sst deletions modulate ischemic retinal damage

\section{References}

Agardh, C.D., Gustavsson, C., Hagert, P., Nilsson, M. \& Agardh, E. (2006) Expression of antioxidant enzymes in rat retinal ischemia followed by reperfusion. Metabolism, 55, 892-898.

Allen, J.P., Hathway, G.J., Clarke, N.J., Jowett, M.I., Topps, S., Kendrick, K.M., Humphrey, P.P., Wilkinson, L.S. \& Emson, P.C. (2003) Somatostatin receptor 2 knockout/lacZ knockin mice show impaired motor coordination and reveal sites of somatostatin action within the striatum. Eur J Neurosci, 17, 1881-1895.

Bagnoli, P., Dal Monte, M. \& Casini, G. (2003) Expression of neuropeptides and their receptors in the developing retina of mammals. Histol Histopathol, 18, 12191242.

Bigiani, A., Petrucci, C., Ghiaroni, V., Dal Monte, M., Cozzi, A., Kreienkamp, H.J., Richter, D. \& Bagnoli, P. (2004) Functional correlates of somatostatin receptor 2 overexpression in the retina of mice with genetic deletion of somatostatin receptor 1. Brain Res, 1025, 177-185.

Bull, N.D. \& Barnett, N.L. (2004) Retinal glutamate transporter activity persists under simulated ischemic conditions. J Neurosci Res, 78, 590-599.

Casini, G., Catalani, E., Dal Monte, M. \& Bagnoli, P. (2005) Functional aspects of the somatostatinergic system in the retina and the potential therapeutic role of somatostatin in retinal disease. Histol Histopathol, 20, 615-632.

Casini, G., Dal Monte, M., Petrucci, C., Gambellini, G., Grouselle, D., Allen, J.P., Kreienkamp, H.J., Richter, D., Epelbaum, J. \& Bagnoli, P. (2004) Altered morphology of rod bipolar cell axonal terminals in the retinas of mice carrying 
E. Catalani et al.

genetic deletion of somatostatin subtype receptor 1 or 2. Eur J Neurosci, 19, 4354.

Celiker, U. \& Ilhan, N. (2002) Nitric oxide and octreotide in retinal ischemiareperfusion injury. Doc Ophthalmol, 105, 327-338.

Cristiani, R., Petrucci, C., Dal Monte, M. \& Bagnoli, P. (2002) Somatostatin (SRIF) and SRIF receptors in the mouse retina. Brain Res, 936, 1-14.

Dal Monte, M., Petrucci, C., Cozzi, A., Allen, J.P. \& Bagnoli, P. (2003a) Somatostatin inhibits potassium-evoked glutamate release by activation of the $\operatorname{sst}(2)$ somatostatin receptor in the mouse retina. Naunyn Schmiedebergs Arch Pharmacol, 367, 188-192.

Dal Monte, M., Petrucci, C., Vasilaki, A., Cervia, D., Grouselle, D., Epelbaum, J., Kreienkamp, H.J., Richter, D., Hoyer, D. \& Bagnoli, P. (2003b) Genetic deletion of somatostatin receptor 1 alters somatostatinergic transmission in the mouse retina. Neuropharmacology, 45, 1080-1092.

Dijk, F. \& Kamphuis, W. (2004) An immunocytochemical study on specific amacrine cell subpopulations in the rat retina after ischemia. Brain Res, 1026, 205-217.

Dijk, F., van Leeuwen, S. \& Kamphuis, W. (2004) Differential effects of ischemia/reperfusion on amacrine cell subtype-specific transcript levels in the rat retina. Brain Res, 1026, 194-204.

Du, Y., Bales, K.R., Dodel, R.C., Hamilton-Byrd, E., Horn, J.W., Czilli, D.L., Simmons, L.K., Ni, B. \& Paul, S.M. (1997) Activation of a caspase 3-related cysteine protease is required for glutamate-mediated apoptosis of cultured cerebellar granule neurons. Proc Natl Acad Sci U S A, 94, 11657-11662. 
sst deletions modulate ischemic retinal damage

Endo, S., Tomita, H., Ishiguro, S. \& Tamai, M. (2002) Effect of betaxolol on aspartate aminotransferase activity in hypoxic rat retina in vitro. Jpn J Pharmacol, 90, 121-124.

Gabriel, R., de Souza, S., Ziff, E.B. \& Witkovsky, P. (2002) Association of the AMPA receptor-related postsynaptic density proteins GRIP and ABP with subsets of glutamate-sensitive neurons in the rat retina. J Comp Neurol, 449, 129-140.

Izumi, Y., Hammerman, S.B., Kirby, C.O., Benz, A.M., Olney, J.W. \& Zorumski, C.F. (2003) Involvement of glutamate in ischemic neurodegeneration in isolated retina. Vis Neurosci, 20, 97-107.

Katai, N. \& Yoshimura, N. (1999) Apoptotic retinal neuronal death by ischemiareperfusion is executed by two distinct caspase family proteases. Invest Ophthalmol Vis Sci, 40, 2697-2705.

Kinukawa, J., Shimura, M., Harata, N. \& Tamai, M. (2005) Gliclazide attenuates the intracellular $\mathrm{Ca} 2+$ changes induced in vitro by ischemia in the retinal slices of rats with streptozotocin-induced diabetes. Curr Eye Res, 30, 789-798.

Kouvidi, E., Papadopoulou-Daifoti, Z. \& Thermos, K. (2006) Somatostatin modulates dopamine release in rat retina. Neurosci Lett, 391, 82-86.

Kreienkamp, H.J., Akgun, E., Baumeister, H., Meyerhof, W. \& Richter, D. (1999) Somatostatin receptor subtype 1 modulates basal inhibition of growth hormone release in somatotrophs. FEBS Lett, 462, 464-466.

Kuriyama, H., Nakagawa, M. \& Tsuda, M. (2001) Intracellular Ca(2+) changes induced by in vitro ischemia in rat retinal slices. Exp Eye Res, 73, 365-374.

Li, Y., Li, A.C., Shi, H., Zhou, S., Shou, W.Z., Jiang, X., Naidong, W. \& Lauterbach, J.H. (2005) The use of chemical derivatization to enhance liquid 
E. Catalani et al.

chromatography/tandem mass spectrometric determination of 1-hydroxypyrene, a biomarker for polycyclic aromatic hydrocarbons in human urine. Rapid Commun Mass Spectrom, 19, 3331-3338.

Luo, X., Lambrou, G.N., Sahel, J.A. \& Hicks, D. (2001) Hypoglycemia induces general neuronal death, whereas hypoxia and glutamate transport blockade lead to selective retinal ganglion cell death in vitro. Invest Ophthalmol Vis Sci, 42, 2695-2705.

Mastrodimou, N., Lambrou, G.N. \& Thermos, K. (2005) Effect of somatostatin analogues on chemically induced ischaemia in the rat retina. Naunyn Schmiedebergs Arch Pharmacol, 371, 44-53.

Mastrodimou, N. \& Thermos, K. (2004) The somatostatin receptor (sst1) modulates the release of somatostatin in rat retina. Neurosci Lett, 356, 13-16.

Maynard, K.I., Arango, P.M., Chen, D. \& Ogilvy, C.S. (1998) Acetylsalicylate administered during simulated ischemia reduces the recovery of neuronal function in the in vitro rabbit retina. Neurosci Lett, 249, 159-162.

Napper, G.A., Pianta, M.J. \& Kalloniatis, M. (2001) Localization of amino acid neurotransmitters following in vitro ischemia and anoxia in the rat retina. Vis Neurosci, 18, 413-427.

Neal, M.J., Cunningham, J.R., Hutson, P.H. \& Hogg, J. (1994) Effects of ischaemia on neurotransmitter release from the isolated retina. J Neurochem, 62, 1025-1033.

Osborne, N.N., Casson, R.J., Wood, J.P., Chidlow, G., Graham, M. \& Melena, J. (2004) Retinal ischemia: mechanisms of damage and potential therapeutic strategies. Prog Retin Eye Res, 23, 91-147. 
Osborne, N.N., Cazevieille, C., Carvalho, A.L., Larsen, A.K. \& DeSantis, L. (1997) In vivo and in vitro experiments show that betaxolol is a retinal neuroprotective agent. Brain Res, 751, 113-123.

Pavan, B., Fiorini, S., Dal Monte, M., Lunghi, L., Biondi, C., Bagnoli, P. \& Cervia, D. (2004) Somatostatin coupling to adenylyl cyclase activity in the mouse retina. Naunyn Schmiedebergs Arch Pharmacol, 370, 91-98.

Payet, O., Maurin, L., Bonne, C. \& Muller, A. (2004) Hypoxia stimulates glutamate uptake in whole rat retinal cells in vitro. Neurosci Lett, 356, 148-150.

Quinones-Hinojosa, A., Ames, A., 3rd, Malek, J.Y. \& Maynard, K.I. (1999) An in vitro rabbit retina model to study electrophysiologic and metabolic function during and following ischemia. J Neurosci Methods, 90, 107-115.

Sun, D. \& Kalloniatis, M. (2006) Mapping glutamate responses in immunocytochemically identified neurons of the mouse retina. J Comp Neurol, 494, 686-703.

Tamada, Y., Fukiage, C., Daibo, S., Yoshida, Y., Azuma, M. \& Shearer, T.R. (2002) Involvement of calpain in hypoxia-induced damage in rat retina in vitro. Comp Biochem Physiol B Biochem Mol Biol, 131, 221-225.

Tenneti, L. \& Lipton, S.A. (2000) Involvement of activated caspase-3-like proteases in $\mathrm{N}$-methyl-D-aspartate-induced apoptosis in cerebrocortical neurons. $J$ Neurochem, 74, 134-142.

Tezel, G. \& Wax, M.B. (1999) Inhibition of caspase activity in retinal cell apoptosis induced by various stimuli in vitro. Invest Ophthalmol Vis Sci, 40, 2660-2667.

Thermos, K. (2003) Functional mapping of somatostatin receptors in the retina: a review. Vision Res, 43, 1805-1815. 
E. Catalani et al.

Ueda, M., Fujita, R., Koji, T. \& Ueda, H. (2004) The cognition-enhancer nefiracetam inhibits both necrosis and apoptosis in retinal ischemic models in vitro and in vivo. J Pharmacol Exp Ther, 309, 200-207.

Vasilaki, A., Mouratidou, M., Schulz, S. \& Thermos, K. (2002) Somatostatin mediates nitric oxide production by activating sst(2) receptors in the rat retina.

Neuropharmacology, 43, 899-909.

Won, S.J., Kim, D.Y. \& Gwag, B.J. (2002) Cellular and molecular pathways of ischemic neuronal death. J Biochem Mol Biol, 35, 67-86.

Yamamoto, H., Schmidt-Kastner, R., Hamasaki, D.I. \& Parel, J.M. (2006) Complex neurodegeneration in retina following moderate ischemia induced by bilateral common carotid artery occlusion in Wistar rats. Exp Eye Res, 82, 767-779.

Zheng, H., Bailey, A., Jiang, M.H., Honda, K., Chen, H.Y., Trumbauer, M.E., Van der Ploeg, L.H., Schaeffer, J.M., Leng, G. \& Smith, R.G. (1997) Somatostatin receptor subtype 2 knockout mice are refractory to growth hormone-negative feedback on arcuate neurons. Mol Endocrinol, 11, 1709-1717. 
sst deletions modulate ischemic retinal damage

TABLE 1. Immunohistochemical markers after $1 \mathrm{~h}$ ischemic treatment in WT, $\mathrm{sst}_{1} \mathrm{KO}$ and $\mathrm{sst}_{2} \mathrm{KO}$ retinas

\begin{tabular}{|c|c|c|c|c|}
\hline Marker & Control & WT & $\mathrm{sst}_{1} \mathrm{KO}$ & $\mathrm{sst}_{2} \mathrm{KO}$ \\
\hline Cone arrestin & +++ & +++ & +++ & +++ \\
\hline GAT-1 & +++ & +++ & +++ & +++ \\
\hline$\beta$-Tubulin & +++ & ++ & ++ & ++ \\
\hline$T H$ & +++ & ++ & $+++*$ & $+++*$ \\
\hline$P K C$ & +++ & ++ & $+++*$ & $+{ }^{\#}$ \\
\hline $\mathrm{G} \gamma 13$ & +++ & $+/-$ & $+/-$ & $+/-$ \\
\hline SRIF & +++ & $+/-$ & $+/-$ & $+/-$ \\
\hline Calbindin & +++ & - & - & - \\
\hline$M A b 115 A 10$ & +++ & - & $+/-*$ & - \\
\hline CaBP5 & +++ & - & $++*$ & - \\
\hline ChAT & +++ & - & - & - \\
\hline
\end{tabular}

Markers in italic are those who displayed differences between WT and sst $_{1} \mathrm{KO}$ and/or sst $_{2} \mathrm{KO}$ retinas. ${ }^{*}$ increase with respect to WT; ${ }^{\#}$ decrease with respect to WT. 
E. Catalani et al.

TABLE 2. Immunohistochemical markers after $3 \mathrm{~h}$ or $6 \mathrm{~h}$ ischemic treatment in $\mathrm{WT}, \mathrm{sst}_{1}$ $\mathrm{KO}$ and $\mathrm{sst}_{2} \mathrm{KO}$ retinas

\begin{tabular}{lcccc}
\hline \multicolumn{1}{c}{ Marker } & Control & WT & sst $_{1} \mathrm{KO}$ & sst $_{2} \mathrm{KO}$ \\
\hline TH $(3 \mathrm{~h})$ & +++ & ++ & +++ & +++ \\
PKC $(3 \mathrm{~h})$ & +++ & + & ++ & $+/-$ \\
CaBP5 $(3 \mathrm{~h})$ & +++ & - & + & - \\
TH $(6 \mathrm{~h})$ & +++ & + & +++ & +++ \\
PKC $(6 \mathrm{~h})$ & +++ & $+/-$ & + & - \\
CaBP5 $(6 \mathrm{~h})$ & +++ & - & $+/-$ & - \\
\hline
\end{tabular}


sst deletions modulate ischemic retinal damage

\section{Figure legends}

Fig 1. Summary of TUNEL labeling in WT and in $\mathrm{sst}_{1}$ or $\mathrm{sst}_{2} \mathrm{KO}$ ischemic retinas. Each panel shows the DAPI staining (on the left), the TUNEL labeling (in the center) and the thresholded TUNEL image (on the right). (A), (B) and (C) represent the WT ischemic retina after $1 \mathrm{~h}, 3 \mathrm{~h}$ or $6 \mathrm{~h}$ incubation, respectively, in ischemic conditions. It is apparent that the amount of TUNEL labeling in the ONL, INL and GCL increases with increasing incubation times. Panel (D) shows a $\mathrm{sst}_{1} \mathrm{KO}$ retina after $1 \mathrm{~h}$ ischemia. In this case, the amount of TUNEL staining appears to be reduced in all nuclear layers as compared with the $1 \mathrm{~h}$ ischemic WT retina (A). In contrast, the TUNEL labeling in the $1 \mathrm{~h}$ ischemic $\mathrm{sst}_{2} \mathrm{KO}$ retina (E) is similar to that in the WT (A). (F) shows sections, stained with both DAPI (left half of each photomicrograph) and TUNEL (right half), of WT, sst ${ }_{1}$ and $\mathrm{sst}_{2} \mathrm{KO}$ retinas incubated for $3 \mathrm{~h}$ in control conditions. Note the absence of TUNEL labeling. Similar pictures could be observed after $1 \mathrm{~h}$ or $6 \mathrm{~h}$ incubation in control conditions. Scale bar: $20 \mu \mathrm{m}$.

Fig 2. (A) Quantitative evaluation of TUNEL labeling in the ONL, INL and GCL after 1,3 or $6 \mathrm{~h}$ ischemic treatment. $* \mathrm{p}<0.05$, and $* * \mathrm{p}<0.001$ vs respective $1 \mathrm{~h}$ values; $\S$ $\mathrm{p}<0.001 v s$ respective $3 \mathrm{~h}$ values (ANOVA and Tukey's post test). (B) Percentage of cell death in the ONL, INL and GCL after $1 \mathrm{~h}$ ischemic treatment in WT, sst $\mathrm{KO}$ and $\mathrm{sst}_{2} \mathrm{KO}$ retinas. ${ }^{*} \mathrm{p}<0.001$ vs WT (ANOVA and Tukey's post test). Inset: TUNEL labeling after $3 \mathrm{~h}$ ischemic treatment in WT (light gray) and $\mathrm{sst}_{1} \mathrm{KO}$ (dark 
E. Catalani et al.

gray) retinas. The histograms represent means \pm S.E.M. with $\mathrm{N}$ ranging from 20 to 80.

Fig 3. (A) Caspase- 3 mRNA in WT retinas after $1 \mathrm{~h}, 3 \mathrm{~h}$ and $6 \mathrm{~h}$ ischemic treatment as evaluated by semi-quantitative RT-PCR using cyclophilin B mRNA as an internal standard. The control band (indicated with " $\mathrm{C}$ " in panel A) was from retinas incubated for $1 \mathrm{~h}$ in control conditions and it was similar to those obtained after $3 \mathrm{~h}$ or $6 \mathrm{~h}(\mathrm{~N}=3$, data not shown). As shown by the optical density (OD) measurements (B), the levels of caspase-3 mRNA in control retinas (filled bars) were similar at all the tested time periods. In contrast, they were significantly higher after $1 \mathrm{~h}$ ischemia and significantly lower after $3 \mathrm{~h}$ ischemia (gray bars; ${ }^{*} \mathrm{p}<0.001$, ANOVA and Tukey's post test, $\mathrm{N}=3$ for each histogram). After $6 \mathrm{~h}$ ischemia, caspase-3 mRNA was not detected. (C) RT-PCR products corresponding to caspase-3 mRNA after $1 \mathrm{~h}$ ischemic treatment in WT and in $\mathrm{sst}_{1} \mathrm{KO}$ retinas. (D) Caspase-3 mRNA expression in $1 \mathrm{~h}$ ischemic $\mathrm{sst}_{1} \mathrm{KO}$ retinas was significantly lower than in 1h ischemic WT retinas. MW, molecular weight. *p<0.0001, paired Student's $t$ test, $\mathrm{N}=5$ for both WT and $\mathrm{sst}_{1} \mathrm{KO}$.

Fig 4. Summary of immunohistochemical markers of classes (i)-(iii) in WT control and ischemic retinas. Class (i): Arrestin-immunostained cone photoreceptors (A) and GAT-1 immunolabeled amacrine cells (B). Class (ii): $\beta$ tubulin immunostaining in ganglion cells (C); TH-containing amacrine cells (D) and PKC-expressing rod bipolar cells (E). The arrows in (D) indicate TH-immunopositive, varicose processes in the middle IPL and in the INL/OPL of control retinas. The arrows in 
(E) point to swellings in the proximal part of the axons of rod bipolar cells after $1 \mathrm{~h}$ ischemic treatment. Class (iii): G $\gamma 13$-immunostaining in ON-type bipolar cells (F) and SRIF-containing amacrine cells (G). Scale bar: $20 \mu \mathrm{m}$.

Fig 5. TH immunolabeling in $\mathrm{WT}(\mathrm{A}), \mathrm{sst}_{1} \mathrm{KO}(\mathrm{B})$ and in $\mathrm{sst}_{2} \mathrm{KO}(\mathrm{C})$ retinas in control conditions and after $1 \mathrm{~h}$ or $3 \mathrm{~h}$ ischemic treatment. In contrast to WT retinas, the TH-containing fibers in both $\mathrm{KO}$ strains do not appear to be affected by the ischemic treatment. Scale bar: $20 \mu \mathrm{m}$.

Fig 6. $P K C$ immunolabeling in $\mathrm{WT}(\mathrm{A}), \mathrm{sst}_{1} \mathrm{KO}(\mathrm{B})$ and in $\mathrm{sst}_{2} \mathrm{KO}(\mathrm{C})$ retinas in control conditions and after $1 \mathrm{~h}$ or $3 \mathrm{~h}$ ischemic treatment. Compared to WT retinas, rod bipolar cells appear to be less affected by ischemia in sst $_{1} \mathrm{KO}$ retinas, while they are more severely damaged in $\mathrm{sst}_{2} \mathrm{KO}$ retinas. Scale bar: $20 \mu \mathrm{m}$.

Fig 7. CaBP5 immunolabeling in $\mathrm{WT}(\mathrm{A}), \mathrm{sst}_{1} \mathrm{KO}(\mathrm{B})$ and in $\mathrm{sst}_{2} \mathrm{KO}(\mathrm{C})$ retinas in control conditions and after $1 \mathrm{~h}$ or $3 \mathrm{~h}$ ischemic treatment. In contrast to WT and $\mathrm{sst}_{2} \mathrm{KO}$ retinas, CaBP5-immunoreactive bipolar cells are present in $\mathrm{sst}_{1} \mathrm{KO}$ retinas after $1 \mathrm{~h}$ ischemic treatment. CaBP5 immunostaining can also be detected after $3 \mathrm{~h}$ ischemia. Scale bar: $20 \mu \mathrm{m}$.

Fig 8. (A) Rate of glutamate release in WT control and in ischemic retinas after $1 \mathrm{~h}, 3 \mathrm{~h}$ or $6 \mathrm{~h}$ incubation. Glutamate release increases with increasing duration of the ischemic treatment $* \mathrm{p}<0.001$ vs respective control values; $\S \mathrm{p}<0.001$ vs respective 1h value (ANOVA and Tukey's multiple comparison test). $\mathrm{N}=3$ in all cases, 
except $\mathrm{N}=6$ in the control at $1 \mathrm{~h}$ incubation. (B) Rate of glutamate release in WT and in $\mathrm{sst}_{1} \mathrm{KO}$ ischemic retinas after $1 \mathrm{~h}$ or $3 \mathrm{~h}$ incubation. Each histogram represent the percent value relative to the respective control value (dashed line). Glutamate release in the ischemic sst ${ }_{1} \mathrm{KO}$ retina is significantly smaller than in ischemic WT retinas. ${ }^{*} \mathrm{p}<0.001$ vs respective WT values (ANOVA and Tukey's multiple comparison test). $\mathrm{N}=3$ in all cases. 

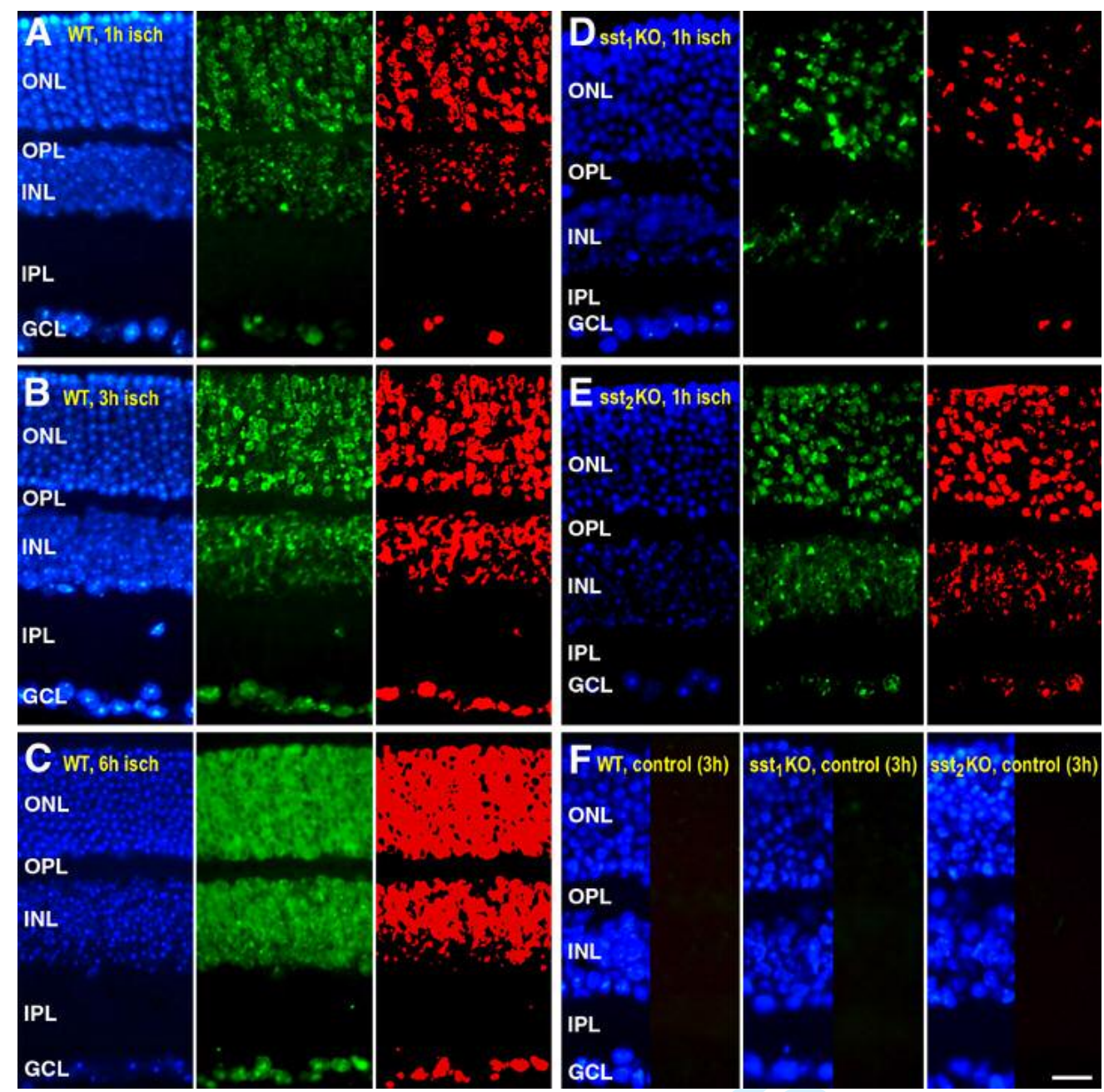

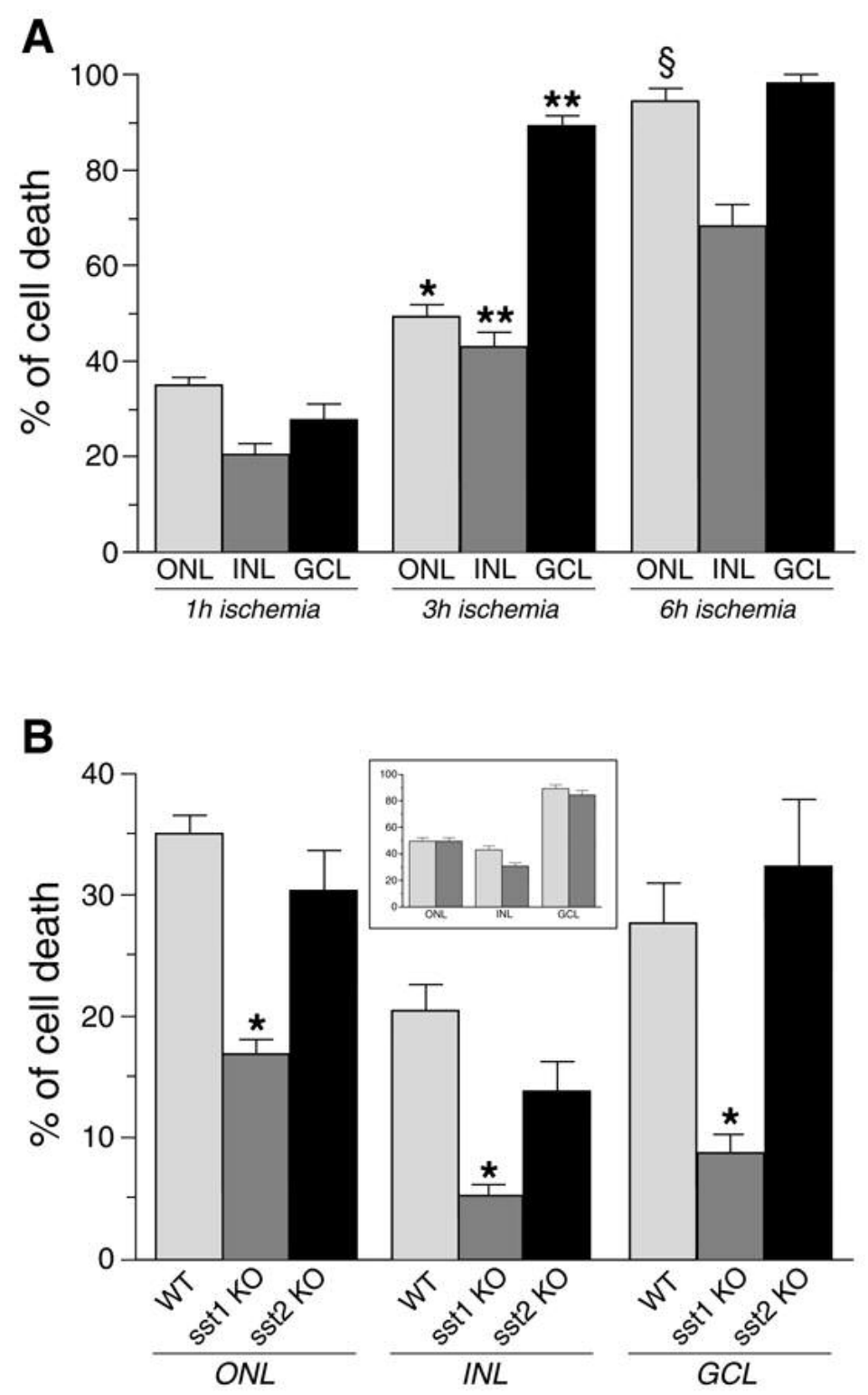


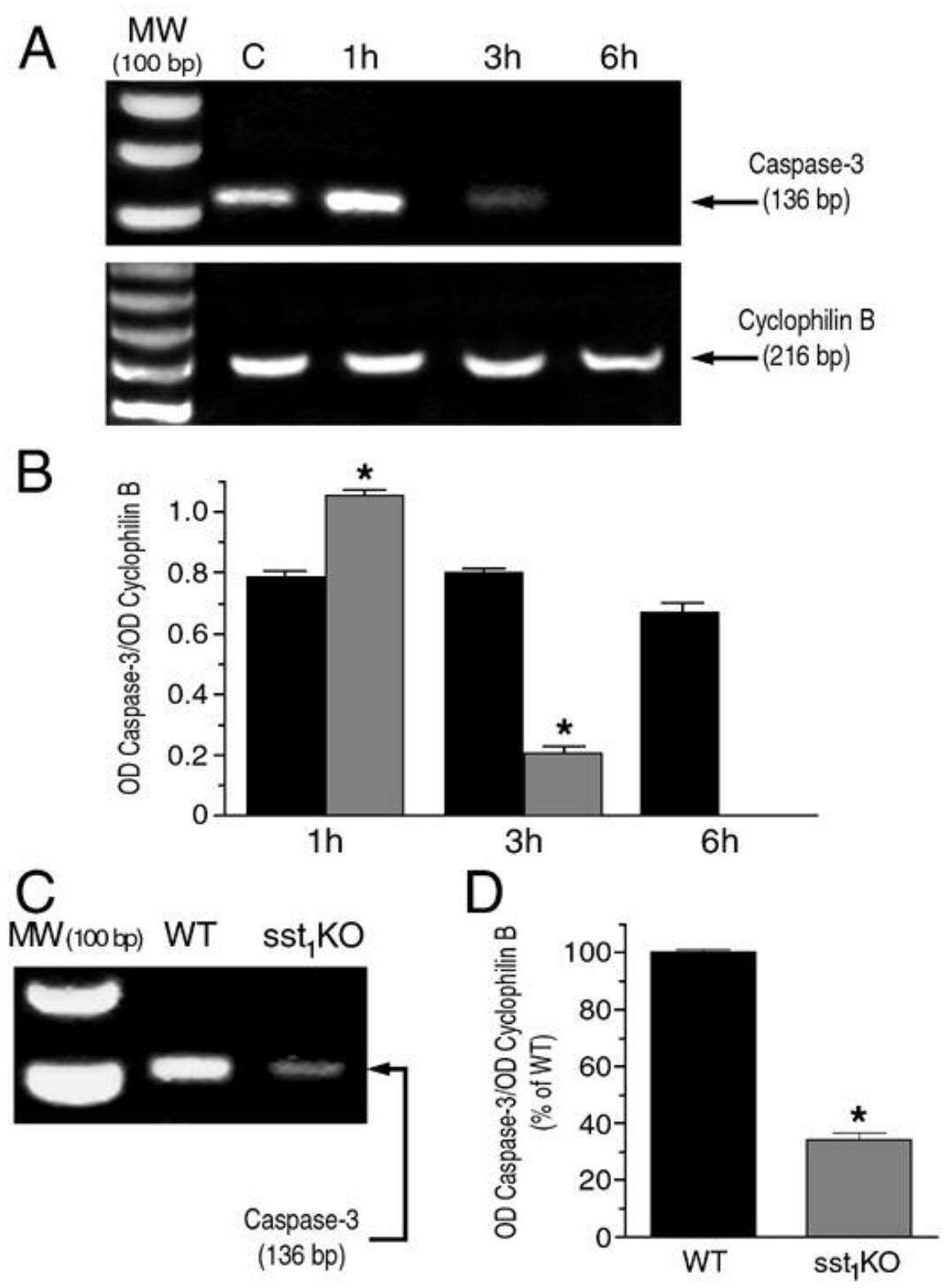




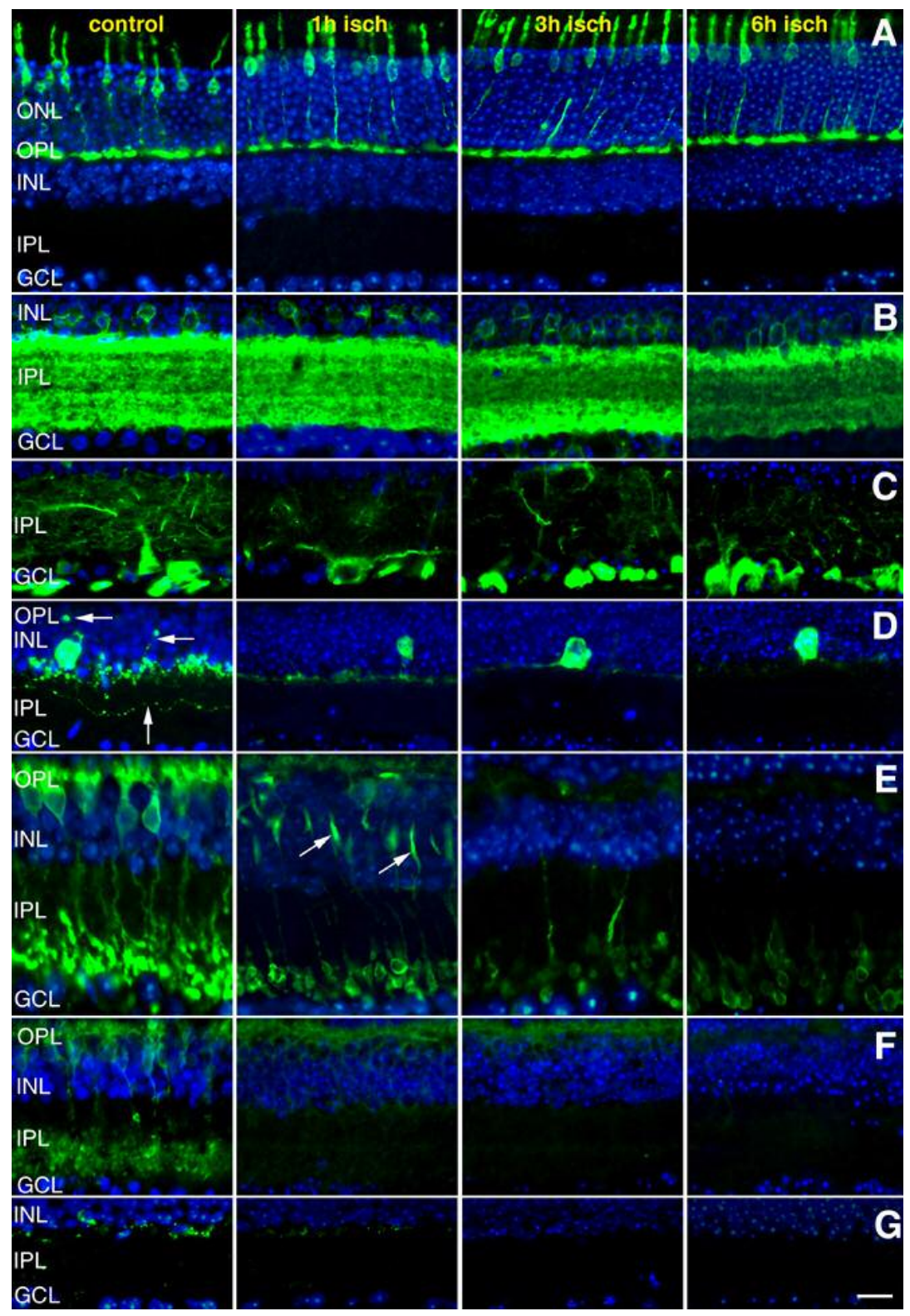



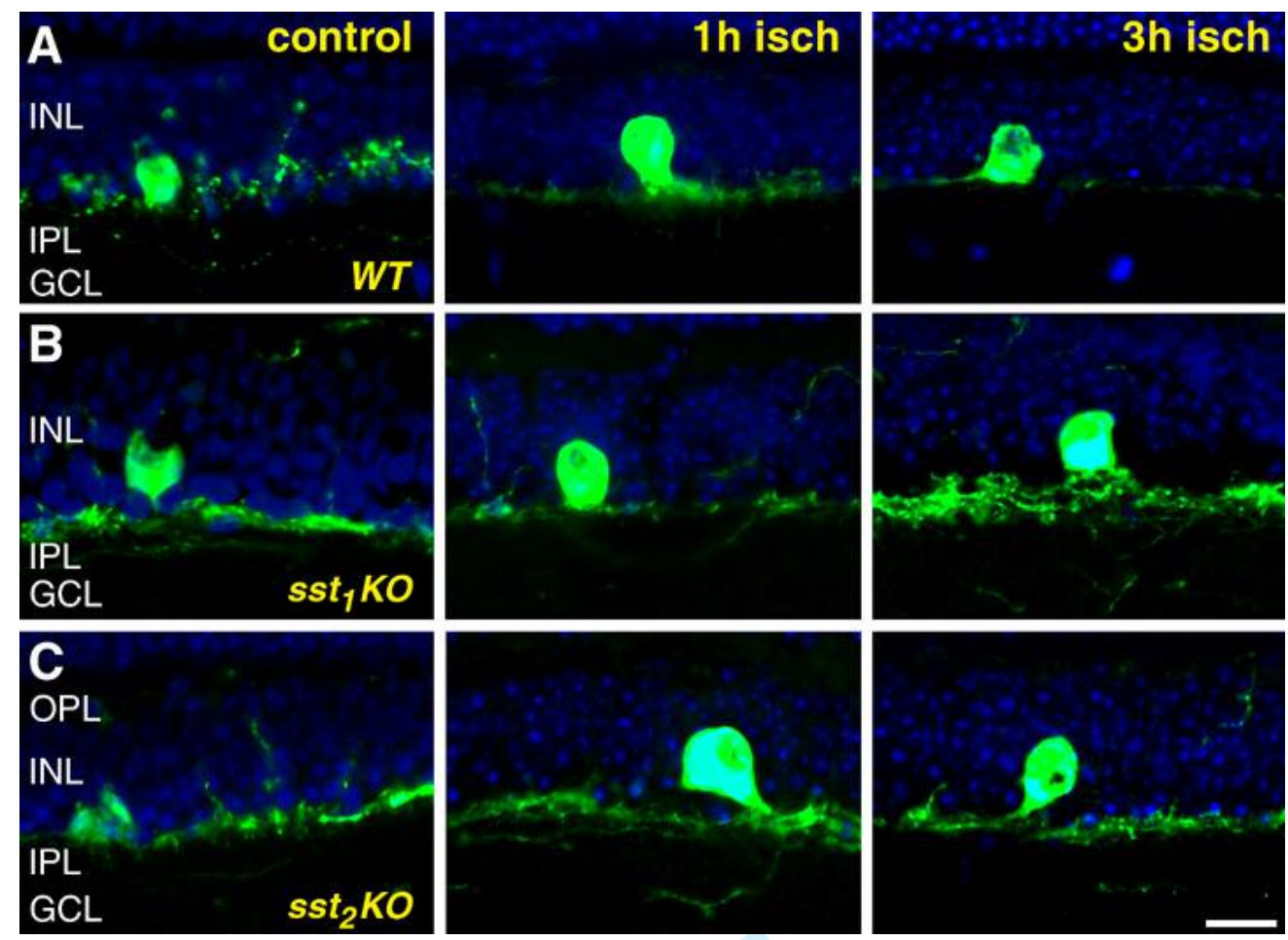

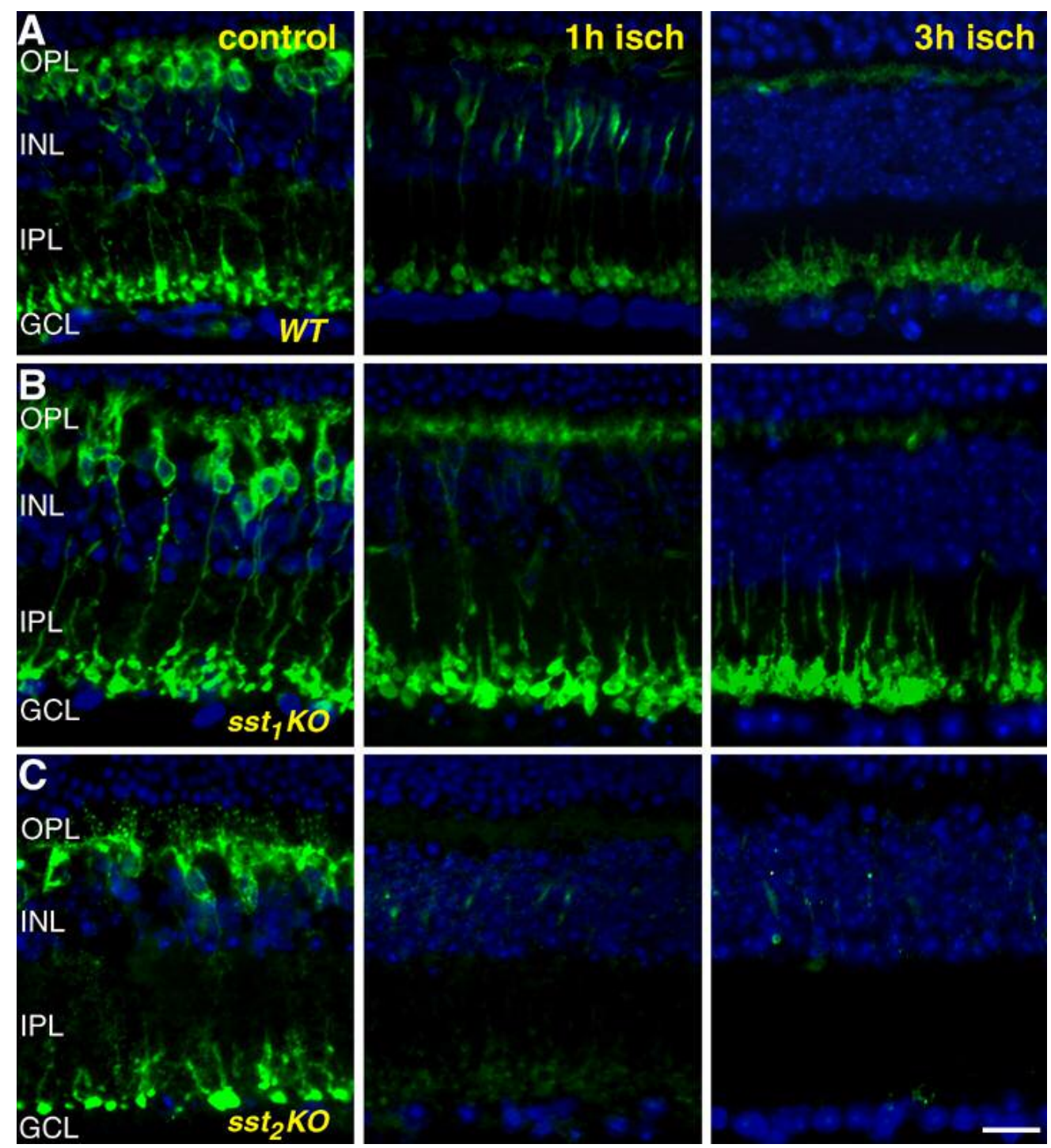


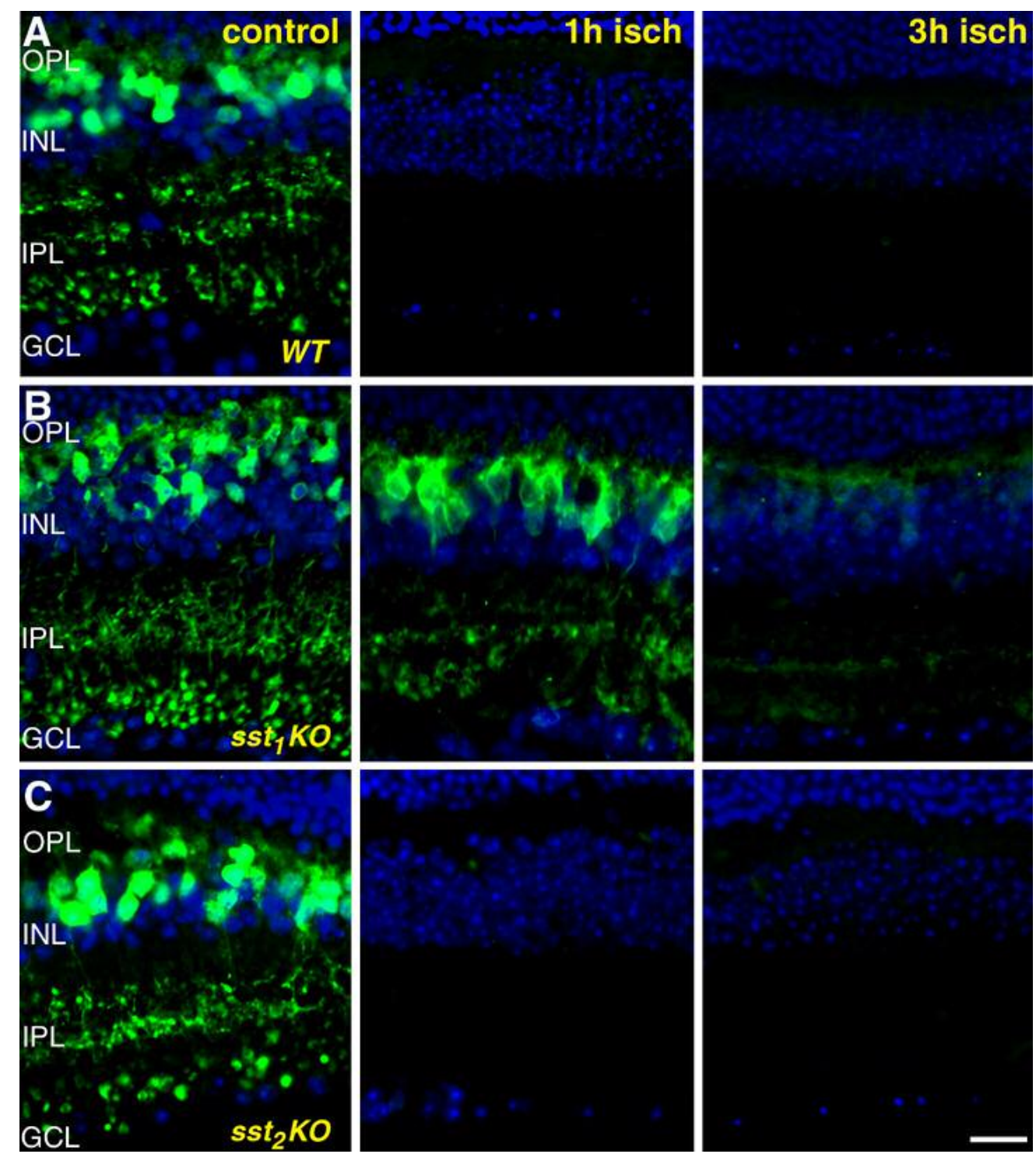



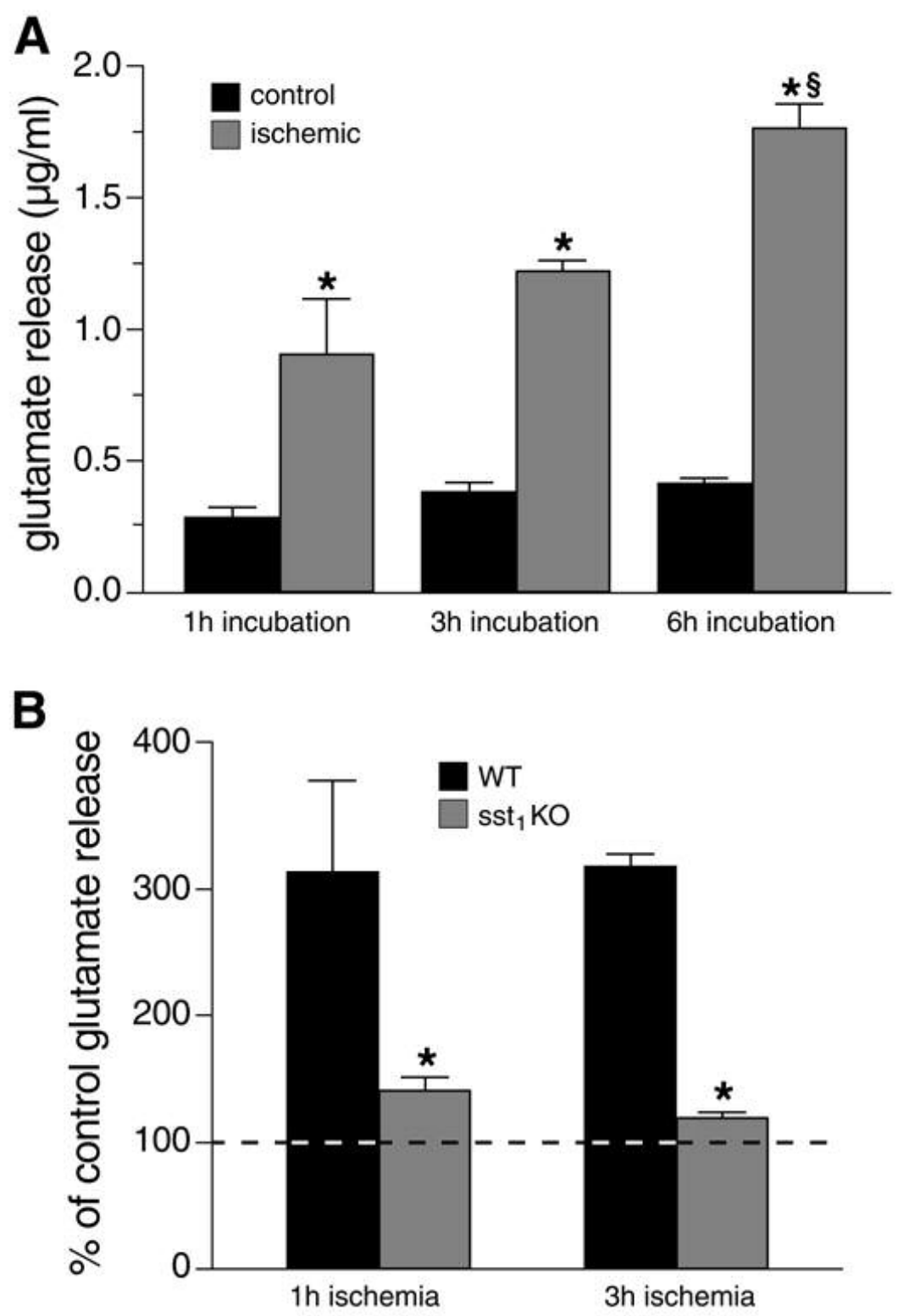